\title{
BMJ Open Systematic review of systematic reviews of non-pharmacological interventions to treat behavioural disturbances in older patients with dementia. The SENATOR-OnTop series
}

Iosief Abraha, ${ }^{1}$ Joseph M Rimland, ${ }^{1}$ Fabiana Mirella Trotta, ${ }^{1}$ Giuseppina Dell'Aquila, ${ }^{1}$ Alfonso Cruz-Jentoft, ${ }^{2}$ Mirko Petrovic, ${ }^{3}$ Adalsteinn Gudmundsson, ${ }^{4}$ Roy Soiza, ${ }^{5}$ Denis O'Mahony, ${ }^{6}$ Antonio Guaita, ${ }^{7}$ Antonio Cherubini ${ }^{1}$

To cite: Abraha I, Rimland JM, Trotta FM, et al. Systematic review of systematic reviews of nonpharmacological interventions to treat behavioural disturbances in older patients with dementia. The SENATOR-OnTop series. BMJ Open 2017;7:e012759. doi:10.1136/bmjopen-2016012759

- Prepublication history and additional material is available. To view please visit the journal (http://dx.doi.org/ 10.1136/bmjopen-2016012759).

Received 23 May 2016 Revised 5 September 2016 Accepted 4 October 2016

CrossMark

For numbered affiliations see end of article.

Correspondence to Dr losief Abraha; iosief_a@yahoo.it

\section{ABSTRACT}

Objective: To provide an overview of nonpharmacological interventions for behavioural and psychological symptoms in dementia (BPSD).

Design: Systematic overview of reviews.

Data sources: PubMed, EMBASE, Cochrane Database of Systematic Reviews, CINAHL and PsycINFO (2009March 2015).

Eligibility criteria: Systematic reviews (SRs) that included at least one comparative study evaluating any non-pharmacological intervention, to treat BPSD.

Data extraction: Eligible studies were selected and data extracted independently by 2 reviewers.

The AMSTAR checklist was used to assess the quality of the SRs.

Data analysis: Extracted data were synthesised using a narrative approach.

Results: 38 SRs and 142 primary studies were identified, comprising the following categories of nonpharmacological interventions: (1) sensory stimulation interventions (12 SRs, 27 primary studies) that encompassed: acupressure, aromatherapy, massage/ touch therapy, light therapy and sensory garden; (2) cognitive/emotion-oriented interventions (33 SRs; 70 primary studies) that included cognitive stimulation, music/dance therapy, dance therapy, snoezelen, transcutaneous electrical nerve stimulation, reminiscence therapy, validation therapy, simulated presence therapy; (3) behaviour management techniques (6 SRs; 32 primary studies) and (4) other therapies (5 SRs, 12 primary studies) comprising exercise therapy, animal-assisted therapy, special care unit and dining room environment-based interventions. Music therapy was effective in reducing agitation (SMD, $-0.49 ; 95 \% \mathrm{Cl}-0.82$ to $-0.17 ; \mathrm{p}=0.003$ ), and anxiety (SMD, $-0.64 ; 95 \% \mathrm{Cl}-1.05$ to -0.24 ; $p=0.002$ ). Home-based behavioural management techniques, caregiver-based interventions or staff training in communication skills, person-centred care or dementia care mapping with supervision during

\section{Strengths and limitations of this study}

Non-pharmacological interventions have gained increasing attention in recent years as an alternative first-line approach to treat behavioural and psychological symptoms in dementia (BPSD).

- The strength of this review is its extensive, comprehensive systematic search of studies that investigated non-pharmacological interventions for BPSD. It provides a compendium of the types of non-pharmacological interventions, including the component of each single intervention, the dosage (when available) and the duration of the treatment.

- Primary studies were generally of limited sample size; there was substantial variation in the characteristics of the intervention and the authors of primary studies reported different conceptual frameworks, and sometimes broad, and quite generic descriptions, of the interventions.

implementation were found to be effective for symptomatic and severe agitation.

Conclusions: A large number of non-pharmacological interventions for BPSD were identified. The majority of the studies had great variation in how the same type of intervention was defined and applied, the follow-up duration, the type of outcome measured, usually with modest sample size. Overall, music therapy and behavioural management techniques were effective for reducing BPSD.

\section{INTRODUCTION}

Dementia is a neuropsychiatric syndrome characterised by cognitive decline and progressive deterioration of daily function, often associated with behavioural disturbances. 
The prevalence of dementia in older participants is reported to be $\sim 6 \%$ worldwide $^{1}$ and, with global population ageing, it is expected to rise, although some recent studies have suggested declining trends in dementia frequency. ${ }^{2}$ Dementia presents a considerable burden to families and caregivers and is becoming a major challenge for all healthcare systems, as well as for society at large. ${ }^{34}$ Alzheimer's disease (AD) is the most common form of dementia in older people, accounting for $60 \%$ of cases.

Approximately five out of every six patients with dementia, including those living at home, will develop behavioural and psychological symptoms during the course of the disease ${ }^{5-8}$ Behavioural and psychological symptoms in dementia (BPSD) are defined as signs and symptoms of disturbed behaviour, mood, thought or perception. ${ }^{9}$ These disturbances, namely agitation, depression, elation, delusions and hallucinations, are strongly correlated with each other. ${ }^{10}{ }^{11}$ Twenty per cent of those initially without symptoms will manifest them within 2 years of dementia diagnosis, ${ }^{12}$ whereas $50-80 \%$ of those with clinically important symptoms remain agitated for several months. ${ }^{13}$ In addition, at least $50 \%$ of patients with dementia present with significant BPSD on a monthly basis. ${ }^{14}$ Agitation, together with depression, hinder activities and relationships, cause feelings of helplessness and distress in families and formal caregivers ${ }^{15}$ and are strong predictors for poor quality of life, ${ }^{16}$ as well as nursing home admission. ${ }^{17}$

Currently, options for treating BPSD include pharmacological and non-pharmacological therapies. ${ }^{18}{ }^{19}$ Psychotropic medications are often used to reduce the frequency and severity of BPSD, but in the majority of patients, they provide only modest symptom control. ${ }^{20-22}$ A recent trial reported that the addition of citalopram to psychosocial support significantly reduced agitation and caregiver distress. ${ }^{23}$ However, their adverse effects are common and problematic, in particular the increased risk of falls and fractures ${ }^{24}$ stroke and even mortality. ${ }^{25}$ In addition, there is some evidence that the use of benzodiazepines to treat agitation in patients with dementia may increase cognitive decline ${ }^{24}$ and may expose patients to an immediate risk of injurious falls. ${ }^{26}$ Finally, memantine and cholinesterase inhibitors are considered to be of very limited value to improve agitation in participants with $\mathrm{AD} .{ }^{27} 28$

In general, non-pharmacological interventions are considered a preferable alternative to psychotropic pharmacotherapy for treating BPSD. ${ }^{29}$ However, there is conflicting evidence concerning the efficacy and practicality of non-pharmacological interventions to improve BPSD, particularly agitation. ${ }^{9} 30$

The purpose of the present overview is to assess the evidence supporting these non-pharmacological interventions with a view to providing a working compendium for the non-drug management of BPSD.

The present overview updates the evidence on the same theme gathered by a previous systematic overview published in 2011. ${ }^{31}$

\section{METHODS}

This work is part of the Optimal Evidence-Based Non-drug Therapies in Older People (ONTOP) project, a work package of a European Union funded FP7 research named SENATOR (Software ENgine for the Assessment \& Optimization of drug and non-drug Therapy in Older peRsons). The ONTOP aim is to undertake a literature search of systematic reviews (SRs) and provide clinical recommendations concerning evidence-based non-pharmacological treatments of several prevalent medical conditions affecting older people, including delirium, ${ }^{32} 33$ pressure ulcers, ${ }^{33-35}$ falls, ${ }^{36} 37$ stroke and heart failure. A protocol that describes the search strategy, screening and inclusion criteria, has been previously published. ${ }^{38}$ Briefly, to obtain the evidence regarding the non-pharmacological interventions, we first identified published SRs using a systematic search across several databases. After processing eligible SRs, we identified and obtained primary studies from these SRs to generate the compendium of nonpharmacological interventions. In a subsequent work will present the assessment of the body of evidence and provide recommendations according to the GRADE approach. ${ }^{38}$

\section{Search strategy and inclusion criteria for systematic reviews}

The search sources included the Cochrane Database of Systematic Reviews, PubMed, PsycINFO and CINAHL (see online supplementary appendix 1). Two criteria were considered for further evaluation of an abstract: (1) a paper defined as a review or a meta-analysis; (2) the use of any non-pharmacological intervention to treat behavioural disturbances in patients with dementia. The publication years ranged from 2009 to March 2015.

Subsequently, full-texts of relevant abstracts were obtained and screened to identify SRs of interest based on (1) the use of at least one medical literature database; (2) the inclusion of at least one primary study and (3) the use of at least one non-pharmacological intervention to treat behavioural disturbances in people aged $60+$ years.

We assessed the methodological quality of each SR using the AMSTAR (A Measurement Tool to Assess Reviews) instrument that contains 11 items. $^{39}$ Final grading of the methodological quality of each SR was based on the overall score and reported as either 'high' (score $\geq 8$ ), 'medium' (score 4-7) or 'low' (score $\leq 3$ ). Two reviewers independently assessed the quality of the SRs, and disagreements were resolved by consensus.

\section{Data extraction and management}

From each SR, the following data were collected: the publication year, the databases searched, the study population, the non-pharmacological interventions, the number of primary studies included, the outcome measures and the AMSTAR score. Pairs of reviewers independently screened titles, abstracts and full texts of 
articles. Disagreements were resolved by discussion or, where necessary, by consulting another author.

\section{Outcome measures}

We focused on reviews that considered BPSD, as a primary outcome, measured by (1) multidomain scales (eg, Neuropsychiatric Inventory (NPI), Brief Psychiatric Rating Scale, BPRS), (2) scales specific to agitation (eg, Cohen-Mansfield Agitation Inventory, CMAI) and (3) scales specific to depression or anxiety (eg, Cornell Scale for Depression in Dementia, CSDD).

\section{Inclusion criteria for primary studies and assessment}

From the included SRs, we obtained any experimental comparative study, either randomised or non-randomised, that investigated any non-pharmacological intervention to treat BPSD in older patients. Observational studies or before-after studies, with historical controls, were excluded. As outlined in our protocol, we extracted data from primary studies to perform meta-analyses and heterogeneity was addressed using the Cochrane Collaboration approach. ${ }^{38}$

\section{Risk of bias assessment and grading the quality of evidence}

We used the Cochrane Collaboration method to evaluate the risk of bias. The domains considered were random sequence generation, allocation concealment, ${ }^{40}$ blinding of participants, personnel, or outcome assessor, ${ }^{40}$ incomplete outcome data, ${ }^{41}$ selective reporting ${ }^{42}$ and other potential biases (eg, balance in baseline characteristics). The overall quality of evidence was assessed using the GRADE (Grading of Recommendations, Assessment, Development and Evaluation) methodology that takes into account the risk of bias, consistency of results across the studies, precision of the results, directness and likelihood of publication bias. ${ }^{43}$ Results regarding the risk of bias assessment, and grading the quality of evidence, will be provided in a companion paper.

\section{RESULTS}

Our search strategy identified 4392 abstracts of which 2549 were duplicates and were subsequently removed. After abstract screening, 67 records were identified for full-text assessment. Of these, 38 reviews were included in this overview. From these SRs, we obtained 142 primary studies from which we abstracted details of the non-pharmacological interventions. Figure 1 shows the study screening process. Table 1 depicts the basic characteristics of the included SRs. The characteristics of relevant primary studies are reported in online supplementary appendix 2 as electronic tables (etable). The AMSTAR evaluation are summarised in online supplementary appendix 3 .

The interventions in this overview were classified according to the following categories: (1) sensory stimulation interventions that encompass acupuncture, aromatherapy, massage therapy, light therapy, sensory garden intervention, cognitive stimulation, music/singing and dance therapy, snoezelen and transcutaneous electrical
Figure 1 Study screening process.
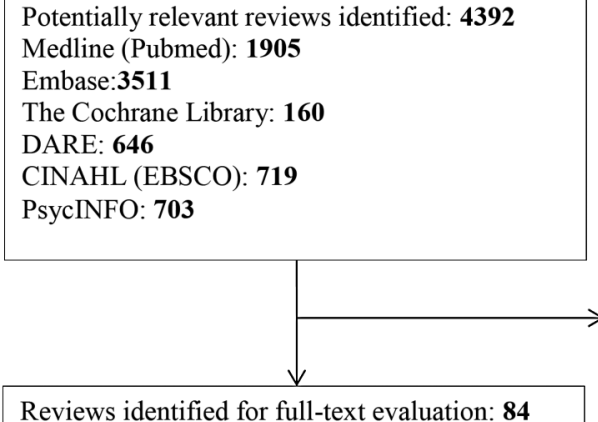

Reviews excluded based on abstract evaluation:4308

Reviews identified for full-text evaluation: $\mathbf{8 4}$

Systematic review/meta-analysis included: $\mathbf{3 8}$
Reviews excluded with reason: $\mathbf{2 3}$ Behavioral outcomes not considered: 12 Caregiver related outcomes: 8 Non-pharmacological interventions not considered: 2

Participants did not have dementia: 1

Primary studies included for evaluation: $\mathbf{1 4 2}$ 
Table 1 Characteristics of included systematic reviews/meta-analyses

\begin{tabular}{|c|c|c|c|c|c|}
\hline Author (year) & Databases searched & Population & $\begin{array}{l}\text { Non-pharmacological } \\
\text { intervention }\end{array}$ & Primary studies & Outcome \\
\hline Aguirre 2013 & $\begin{array}{l}\text { MEDLINE, Embase, Cinahl, } \\
\text { PsycINFO, the Cochrane } \\
\text { Library, Lilacs, trial registers, } \\
\text { grey literature }\end{array}$ & $\begin{array}{l}\text { Participants who had a } \\
\text { diagnosis of dementia } \\
\text { (Alzheimer's disease, } \\
\text { vascular dementia mixed } \\
\text { Alzheimer's and vascular } \\
\text { dementia, other types of } \\
\text { dementia), including all levels } \\
\text { of cognitive impairment }\end{array}$ & Cognitive stimulation & 15 RCTs & $\begin{array}{l}\text { Mood, quality of life, well-being, } \\
\text { ADL, communication, behaviour, } \\
\text { neuropsychiatric symptoms and } \\
\text { social interaction }\end{array}$ \\
\hline Alves 2013 & $\begin{array}{l}\text { MEDLINE, PsycINFO, } \\
\text { Cochrane Library, EMBASE, } \\
\text { metaRegister of Clinical Trials, } \\
\text { OVID all, EBM Reviews }\end{array}$ & $\begin{array}{l}\text { Patients diagnosed with } \\
\text { Alzheimer's disease (without } \\
\text { mild cognitive impairment, } \\
\text { mixed Alzheimer's disease, } \\
\text { vascular dementia, and other } \\
\text { types of dementia such as } \\
\text { frontotemporal dementia or } \\
\text { dementia with Lewy bodies) }\end{array}$ & $\begin{array}{l}\text { Memory-training } \\
\text { program; attention- } \\
\text { stimulating activities; } \\
\text { computerized 'cognitive } \\
\text { training' }\end{array}$ & 4 studies & $\begin{array}{l}\text { Cognitive functioning; ADL; } \\
\text { memory Symptoms; finger } \\
\text { tapping test; depressive } \\
\text { symptoms; QoL; reaction time; } \\
\text { screening of mental status; } \\
\text { neuropsychiatric symptoms }\end{array}$ \\
\hline Bernabei 2013 & MEDLINE, Embase, PsycINFO & $\begin{array}{l}\text { Elderly patients affected by } \\
\text { dementia or psychiatric } \\
\text { disorders }\end{array}$ & $\begin{array}{l}\text { Animal-assisted } \\
\text { interventions }\end{array}$ & $\begin{array}{l}10 \text { studies on BPSD } \\
\text { ( } 3 \text { case-control and } 7 \\
\text { repeated measures } \\
\text { design) }\end{array}$ & Any psychiatric disorder \\
\hline Blake 2013 & $\begin{array}{l}\text { PubMed, Science Direct, the } \\
\text { Cochrane Library and Web of } \\
\text { Knowledge }\end{array}$ & $\begin{array}{l}\text { Adults diagnosed with } \\
\text { dementia who have } \\
\text { depressive symptoms }\end{array}$ & $\begin{array}{l}\text { Reminiscence group } \\
\text { therapy }\end{array}$ & 4 studies & $\begin{array}{l}\text { Change in level of depressive } \\
\text { symptoms }\end{array}$ \\
\hline Carrion 2013 & $\begin{array}{l}\text { MEDLINE, EMBASE, PASCAL, } \\
\text { the Cochrane Library, National } \\
\text { Guidelines Clearinghouse, Trip } \\
\text { database, HEALTHSTAR, } \\
\text { CINHAL and PsycINFO }\end{array}$ & $\begin{array}{l}\text { Older people diagnosed as } \\
\text { having Alzheimer's disease } \\
\text { or probable Alzheimer's } \\
\text { disease }\end{array}$ & $\begin{array}{l}\text { Cognition-oriented care } \\
\text { approaches: } 1 . \text { Reality } \\
\text { orientation; } 2 \text {. Skills } \\
\text { training }\end{array}$ & $\begin{array}{l}\text { Reality orientation: } \\
9 \text { RCTs;Skills training: } \\
\text { 8 RCTs }\end{array}$ & $\begin{array}{l}\text { Cognitive function; behavioural } \\
\text { symptoms and mood }\end{array}$ \\
\hline $\begin{array}{l}\text { Chaudhury } \\
2013\end{array}$ & $\begin{array}{l}\text { MEDLINE, CINAHL, Ageline, } \\
\text { Web of Science, and Simon } \\
\text { Fraser University library } \\
\text { catalogue }\end{array}$ & $\begin{array}{l}\text { Long-term facility residents } \\
\text { with dementia }\end{array}$ & $\begin{array}{l}\text { Supportive dining } \\
\text { environment }\end{array}$ & $\begin{array}{l}21 \text { studies included: } \\
\text { light therapy ( } 1 \text { study); } \\
\text { music therapy } \\
\text { (3 studies) }\end{array}$ & $\begin{array}{l}\text { Physiological and } \\
\text { sociopsychological aspects of } \\
\text { dining, including caloric intake, } \\
\text { enjoyment in eating and social } \\
\text { interaction }\end{array}$ \\
\hline Collet 2010 & $\begin{array}{l}\text { MEDLINE, PsycINFO and } \\
\text { PubMed }\end{array}$ & $\begin{array}{l}\text { Nursing home patients } \\
\text { suffering from either somatic } \\
\text { illness or dementia combined } \\
\text { with psychiatric disorders or } \\
\text { severe behavioural problems }\end{array}$ & $\begin{array}{l}\text { Psychiatric care and } \\
\text { nursing home care } \\
\text { combination }\end{array}$ & 8 RCTs & $\begin{array}{l}\text { Psychosis and depression, } \\
\text { increase in global functioning, } \\
\text { behaviour disorders, cognition } \\
\text { and ADL }\end{array}$ \\
\hline
\end{tabular}


Table 1 Continued

\begin{tabular}{|c|c|c|c|c|c|}
\hline Author (year) & Databases searched & Population & $\begin{array}{l}\text { Non-pnarmacological } \\
\text { intervention }\end{array}$ & Primary studies & Outcome \\
\hline $\begin{array}{l}\text { Eggenberger } \\
2013\end{array}$ & $\begin{array}{l}\text { MEDLINE, AMED, EMBASE, } \\
\text { PsycINFO, CINAHL, The } \\
\text { Cochrane Library, Gerolit, Web } \\
\text { of Science }\end{array}$ & $\begin{array}{l}\text { People with dementia; } \\
\text { professional and family } \\
\text { caregivers }\end{array}$ & $\begin{array}{l}\text { Communication skills } \\
\text { training by means of } \\
\text { face-to-face interaction }\end{array}$ & 12 RCTs & QoL, social interactions \\
\hline Forbes 2014 & $\begin{array}{l}\text { MEDLINE, EMBASE, the } \\
\text { Cochrane Library, CINAHL, } \\
\text { PsycINFO, LILACS+several } \\
\text { Registries, proceedings+other } \\
\text { sites }\end{array}$ & People with dementia & Light therapy & $\begin{array}{l}5 \text { studies met the } \\
\text { inclusion criteria-only } \\
3 \text { were included in the } \\
\text { analyses because of } \\
\text { inappropriate reported }\end{array}$ & $\begin{array}{l}\text { Sleep, behaviour, mood, and } \\
\text { cognitive disturbances } \\
\text { associated with dementia }\end{array}$ \\
\hline Forrester 2014 & $\begin{array}{l}\text { MEDLINE, EMBASE, the } \\
\text { Cochrane Library, CINAHL, } \\
\text { PsycINFO, LILACS+several } \\
\text { Registries, proceedings+other } \\
\text { sites }\end{array}$ & People with dementia & Aromatherapy & 2 RCTs & $\begin{array}{l}\text { Agitation, behavioural symptoms, } \\
\text { quality of life and adverse effects }\end{array}$ \\
\hline Fung 2012 & $\begin{array}{l}\text { MEDLINE, CINAHL, Cochrane } \\
\text { Library, PsycINFO, Social } \\
\text { Sciences Citation Index, } \\
\text { SCOPUS }\end{array}$ & Participants with dementia & Aromatherapy & $\begin{array}{l}11 \text { studies ( } 5 \text { RCTs; } \\
6 \text { controlled trials) }\end{array}$ & Behavioural problems \\
\hline Gonzalez 2014 & $\begin{array}{l}\text { MEDLINE, AMED, CINAHL, ISI } \\
\text { Web of Knowledge, Embase } \\
\text { and Scopus }\end{array}$ & People with dementia & $\begin{array}{l}\text { Sensory gardens and } \\
\text { horticultural activities }\end{array}$ & 2 RCTs & Agitation levels; cognitive status \\
\hline $\begin{array}{l}\text { Guzman-Garcia } \\
2013\end{array}$ & $\begin{array}{l}\text { MEDLINE, Agelnfo, EBM } \\
\text { Reviews EBSCO-CINAHL, } \\
\text { EMBASE, ISI Web, LILACS, } \\
\text { SCOPUS ZETOC; reference } \\
\text { lists; EthOS-Beta; ACER; } \\
\text { Google;+ }\end{array}$ & $\begin{array}{l}\text { People with dementia living } \\
\text { in long-term care homes }\end{array}$ & $\begin{array}{l}\text { Dance movement } \\
\text { therapy; dance therapy; } \\
\text { Psychomotor } \\
\text { dance-based; Social } \\
\text { dancing }\end{array}$ & 10 studies (1 RCT) & Not specified \\
\hline Kiepe 2012 & MEDLINE and PsycINFO & Patients with mental illness & Dance therapy & $\begin{array}{l}1 \text { study (RCT) for } \\
\text { dementia }\end{array}$ & $\begin{array}{l}\text { Any physical and mental } \\
\text { outcomes }\end{array}$ \\
\hline Kim 2012 & $\begin{array}{l}\text { MEDLINE, CINAHL, ProQuest } \\
\text { Medical Library, and Cochrane } \\
\text { and OT }\end{array}$ & Persons with dementia & Occupational therapy & 9 studies & $\begin{array}{l}\text { Behavioural problems and } \\
\text { depression }\end{array}$ \\
\hline Kverno 2009 & $\begin{array}{l}\text { MEDLINE, CINAHL, PsycINFO, } \\
\text { EMBASE }\end{array}$ & $\begin{array}{l}\text { Individuals diagnosed with } \\
\text { advanced dementia }\end{array}$ & $\begin{array}{l}\text { Any non-pharmacological } \\
\text { intervention }\end{array}$ & 460 primary studies & Neuropsychiatric symptoms \\
\hline Lai 2009 & $\begin{array}{l}\text { MEDLINE, The Cochrane } \\
\text { Library, EMBASE, PsycINFO } \\
\text { and CINAHL }\end{array}$ & $\begin{array}{l}\text { Patients with a confirmed } \\
\text { diagnosis of dementia or } \\
\text { Alzheimer's disease or } \\
\text { related disorders }\end{array}$ & Special care units & $\begin{array}{l}8 \text { non-randomised } \\
\text { studies (O RCT) }\end{array}$ & $\begin{array}{l}\text { Behavioural problems, mood, } \\
\text { use of restraints and } \\
\text { psychotropic medication }\end{array}$ \\
\hline
\end{tabular}

Continued 


\begin{tabular}{|c|c|c|c|c|c|}
\hline Author (year) & Databases searched & Population & $\begin{array}{l}\text { Non-pharmacological } \\
\text { intervention }\end{array}$ & Primary studies & Outcome \\
\hline Livingston 2014 & $\begin{array}{l}\text { MEDLINE; Web of Knowledge; } \\
\text { EMBASE; British Nursing } \\
\text { Index; the Health Technology } \\
\text { Assessment programme } \\
\text { database; PsycINFO; NHS } \\
\text { Evidence; System for } \\
\text { Information on Grey Literature }\end{array}$ & Participants with dementia & $\begin{array}{l}\text { Sensory, psychological } \\
\text { and behavioural } \\
\text { interventions }\end{array}$ & 160 primary studies & Agitation \\
\hline $\begin{array}{l}\text { McDermott } \\
2013\end{array}$ & $\begin{array}{l}\text { MEDLINE, EMBASE, } \\
\text { PsycINFO, CINAHL, Cochrane } \\
\text { Library, Web of Science, J } \\
\text { Music Therapy, and Nordic } \\
\text { Journal of Music Therapy }\end{array}$ & Participants with dementia & Music therapy & $\begin{array}{l}15 \text { studies ( } 6 \text { RCTs; } \\
4 \text { non-randomised trials; } \\
5 \text { before-after studies }\end{array}$ & $\begin{array}{l}\text { Behavioural, psychological } \\
\text { aspects, hormonal and } \\
\text { physiological changes, social } \\
\text { and relational aspects of music } \\
\text { therapy }\end{array}$ \\
\hline $\begin{array}{l}\text { Moniz-Cook } \\
2012\end{array}$ & $\begin{array}{l}\text { MEDLINE, EMBASE, CINAHL, } \\
\text { Psyclnfo and LILACS;+ }\end{array}$ & $\begin{array}{l}\text { People with dementia, } \\
\text { irrespective of its cause or } \\
\text { diagnostic subtype, with } \\
\text { reported BPSD or } \\
\text { 'behaviours that challenge', } \\
\text { receiving support or } \\
\text { treatment from mental health } \\
\text { workers, care staff or family } \\
\text { or other informal caregivers }\end{array}$ & $\begin{array}{l}\text { Formulation-led } \\
\text { individualised } \\
\text { interventions targeting } \\
\text { reduction in the } \\
\text { person's distress and/or } \\
\text { resolution of the } \\
\text { caregivers' } \\
\text { management difficulties }\end{array}$ & 18 trials & $\begin{array}{l}\text { Challenging behaviours (eg, } \\
\text { verbal and physical aggression, } \\
\text { restlessness) and mood } \\
\text { (depression).Changes in } \\
\text { caregiver self-report of reaction } \\
\text { to challenging behaviours. }\end{array}$ \\
\hline Moyle 2013 & $\begin{array}{l}\text { MEDLINE, CINHAL, PsycINFO, } \\
\text { Cochrane Library, Scopus, Web } \\
\text { of Science, Health Reference } \\
\text { Center Academic }\end{array}$ & Older people with dementia: & Massage therapy & $\begin{array}{l}\text { Of } 13 \text { studies identified } \\
\text { only } 1 \text { satisfied the } \\
\text { quality of the inclusion } \\
\text { criteria }\end{array}$ & Agitated behaviour \\
\hline O’Neill 2011 & $\begin{array}{l}\text { MEDLINE, the Cochrane } \\
\text { Library, PsycINFO }\end{array}$ & $\begin{array}{l}\text { Adults with mild, moderate, or } \\
\text { severe dementia }\end{array}$ & $\begin{array}{l}\text { Non-pharmacological } \\
\text { treatments }\end{array}$ & 28 systematic reviews & $\begin{array}{l}\text { Behavioural symptoms of } \\
\text { dementia }\end{array}$ \\
\hline Olazaran 2010 & $\begin{array}{l}\text { MEDLINE, PsycINFO, CINAHL, } \\
\text { Embase, Lilacs and the } \\
\text { Cochrane Dementia and } \\
\text { Cognitive Improvement Group } \\
\text { Specialized Register }\end{array}$ & $\begin{array}{l}\text { People with Alzheimer's } \\
\text { disease and related disorders }\end{array}$ & $\begin{array}{l}\text { Any non-pharmacological } \\
\text { intervention }\end{array}$ & 213 & $\begin{array}{l}\text { Cognition; institutionalization; } \\
\text { ADL; behaviour; mood; QoL; } \\
\text { psychological well-being }\end{array}$ \\
\hline Padilla 2011 & $\begin{array}{l}\text { MEDLINE, the Cochrane } \\
\text { Library, AgeLine, CINAHL, } \\
\text { PsycINFO, EMBASE, and } \\
\text { HealthSTAR, OT Seeker, and } \\
\text { Allied and Complementary } \\
\text { Medicine+reference list }\end{array}$ & $\begin{array}{l}\text { People with Alzheimer's } \\
\text { disease and related } \\
\text { dementias }\end{array}$ & $\begin{array}{l}\text { Environment-based } \\
\text { interventions; } \\
\text { multisensory } \\
\text { approaches; other } \\
\text { interventions }\end{array}$ & $\begin{array}{l}1 \text { cross-overall trial } \\
\text { (environmental-based } \\
\text { intervention) }\end{array}$ & $\begin{array}{l}\text { Performance, affect and } \\
\text { behaviour }\end{array}$ \\
\hline
\end{tabular}


Table 1 Continued

\begin{tabular}{|c|c|c|c|c|c|}
\hline Author (year) & Databases searched & Population & $\begin{array}{l}\text { Non-pharmacological } \\
\text { intervention }\end{array}$ & Primary studies & Outcome \\
\hline Potter 2011 & $\begin{array}{l}\text { MEDLINE, EMBASE, CINAHL, } \\
\text { PsycINFO, AMED, the } \\
\text { Cochrane Library, the UK } \\
\text { National Research Register, } \\
\text { Current Controlled Trials }\end{array}$ & Older people with dementia & $\begin{array}{l}\text { Strength and flexibility; } \\
\text { strength and balance } \\
\text { Tai Chi classes sitting } \\
\text { and standing; walking; } \\
\text { stretching; seated } \\
\text { exercises; balance } \\
\text { training; endurance; } \\
\text { aerobic training }\end{array}$ & 13 RCTs & $\begin{array}{l}\text { Physical functioning, quality of } \\
\text { life anddepression }\end{array}$ \\
\hline Robinson 2011 & $\begin{array}{l}\text { MEDLINE; EBM reviews; } \\
\text { AMED; BNI; CINAHL; EMBASE }\end{array}$ & Not specified & Acupressure & $\begin{array}{l}1 \mathrm{RCT} \text { (of } 71 \\
\text { acupressure studies) }\end{array}$ & Any outcome \\
\hline Salami 2011 & $\begin{array}{l}\text { MEDLINE, EMBASE and the } \\
\text { Cochrane Central Register }\end{array}$ & $\begin{array}{l}\text { People with Alzheimer's } \\
\text { disease }\end{array}$ & $\begin{array}{l}\text { Any treatment option for } \\
\text { sleep disturbance not } \\
\text { attributable to other } \\
\text { clinical conditions }\end{array}$ & 9 RCTs & Sleep disturbance \\
\hline Seitz 2012 & $\begin{array}{l}\text { MEDLINE, EMBASE, } \\
\text { PsycINFO, the Cochrane } \\
\text { Library and Google Scholar }\end{array}$ & People with dementia & $\begin{array}{l}\text { Any } \\
\text { non-pharmacological } \\
\text { intervention }\end{array}$ & 40 studies & Neuropsychiatric symptoms \\
\hline $\begin{array}{l}\text { Subramaniam } \\
2012\end{array}$ & $\begin{array}{l}\text { MEDLINE, PsycINFO, CINAHL, } \\
\text { the Cochrane Library, EMBASE } \\
\text { and Web of Knowledge }\end{array}$ & People with dementia & Reminiscence therapy & 5 RCTs & Psychosocial benefits \\
\hline $\begin{array}{l}\text { Thune-Boyle } \\
2012\end{array}$ & $\begin{array}{l}\text { MEDLINE, EMBASE, } \\
\text { PsycINFO }\end{array}$ & People with dementia & Exercise therapy & 2 RCTs & $\begin{array}{l}\text { Behavioural and psychological } \\
\text { symptoms }\end{array}$ \\
\hline Ueda 2013 & MEDLINE, CINAHL, PsycINFO & People with dementia & Music therapy & $\begin{array}{l}18 \text { of } 20 \text { studies } \\
\text { considered agitation } \\
\text { or anxiety (9 CCT; } \\
9 \text { RCTs) }\end{array}$ & $\begin{array}{l}\text { Behavioral and psychological } \\
\text { symptoms; ADL; cognitive } \\
\text { function }\end{array}$ \\
\hline Vasionyte 2013 & $\begin{array}{l}\text { JSTOR, EBSCO, ERIC, } \\
\text { SCIRUS, MEDLINE, PsycINFO, } \\
\text { Cochrane Library and } \\
\text { ProQuest, the journal } \\
\text { databases SAGE PUB and } \\
\text { Cambridge journals }\end{array}$ & Patients with dementia & Music therapy & $3 \mathrm{RCTs}$ & $\begin{array}{l}\text { Affective, behavioural, cognitive } \\
\text { and physiological outcomes }\end{array}$ \\
\hline Vasse 2010 & $\begin{array}{l}\text { PubMed, PsycINFO, Web of } \\
\text { Science and the Cochrane } \\
\text { library }\end{array}$ & People with dementia & $\begin{array}{l}\text { A walking program } \\
\text { combined with } \\
\text { conversation, group } \\
\text { validation therapy, life } \\
\text { review programs, } \\
\text { cognitive stimulation } \\
\text { therapy, activity therapy } \\
\text { and staff education }\end{array}$ & 9 RCTs & $\begin{array}{l}\text { Communication between } \\
\text { residents with dementia and care } \\
\text { staff; neuropsychiatric symptoms } \\
\text { of residents with dementia. }\end{array}$ \\
\hline
\end{tabular}


Table 1 Continued

\begin{tabular}{|c|c|c|c|c|c|}
\hline Author (year) & Databases searched & Population & $\begin{array}{l}\text { Non-pharmacological } \\
\text { intervention }\end{array}$ & Primary studies & Outcome \\
\hline Wall 2010 & MEDLINE, CINAHL, PsycINFO & Older people with dementia & Music therapy & 4 RCTs & Behaviour and well-being \\
\hline Whear 2014 & $\begin{array}{l}\text { MEDLINE, PsycINFO, Embase, } \\
\text { HMIC, AMED; Cochrane } \\
\text { Library; CINAHL; British } \\
\text { Nursing Index; ASSIA; Social } \\
\text { Science Citation Index; EThOS; } \\
\text { Social Care Online and } \\
\text { OpenGrey November } 2012 \text {. }\end{array}$ & $\begin{array}{l}\text { Elderly residents with } \\
\text { dementia }\end{array}$ & $\begin{array}{l}\text { Mealtime interventions } \\
\text { categorized into four } \\
\text { types: music, changes } \\
\text { to food service, dining } \\
\text { environment alteration, } \\
\text { and group conversation }\end{array}$ & $\begin{array}{l}11 \text { studies ( } 7 \text { time } \\
\text { series repeated } \\
\text { measures; } 3 \text { pre-post } \\
\text { study design; } 1 \\
\text { controlled clinical trial) }\end{array}$ & $\begin{array}{l}\text { Behavioural symptoms (anxiety, } \\
\text { agitation, aggression) }\end{array}$ \\
\hline Woods 2012 & $\begin{array}{l}\text { MEDLINE, the Cochrane } \\
\text { Library, EMBASE, PsycINFO, } \\
\text { CINAHL and LILACS, ongoing } \\
\text { trial databases and grey } \\
\text { literature sources }\end{array}$ & $\begin{array}{l}\text { People with dementia and } \\
\text { their caregivers }\end{array}$ & Cognitive stimulation & 15 RCTs & $\begin{array}{l}\text { Cognitive functioning; mood; } \\
\text { QoL; ADL; behavioural } \\
\text { symptoms; neuropsychiatric } \\
\text { symptoms }\end{array}$ \\
\hline Yu 2009 & $\begin{array}{l}\text { MEDLINE (PubMed), CINAHL, } \\
\text { PsycINFO, and the Cochrane } \\
\text { Library }\end{array}$ & $\begin{array}{l}\text { People with early-stage } \\
\text { Alzheimer's disease and } \\
\text { dementia }\end{array}$ & Cognitive training & 7 RCTs & $\begin{array}{l}\text { Any dementia symptoms in } \\
\text { early-stage Alzheimer's disease } \\
\text { and related dementia. }\end{array}$ \\
\hline $\begin{array}{l}\text { Zimmerman } \\
2013\end{array}$ & $\begin{array}{l}\text { MEDLINE, EMBASE, the } \\
\text { Cochrane Library, the } \\
\text { Cumulative Index to Nursing } \\
\text { and Allied Health Literature, } \\
\text { AgeLine, and PsycINFO }\end{array}$ & $\begin{array}{l}\text { People with dementia in } \\
\text { nursing homes and other } \\
\text { residential long-term care } \\
\text { settings }\end{array}$ & $\begin{array}{l}\text { Effective characteristics } \\
\text { of residential long-term } \\
\text { care }\end{array}$ & $\begin{array}{l}14 \text { studies: } 4 \\
\text { prospective cohort } \\
\text { studies, } 9 \text { RCTs, } 1 \\
\text { non-randomized } \\
\text { controlled trial }\end{array}$ & $\begin{array}{l}\text { Health and psychosocial } \\
\text { outcomes }\end{array}$ \\
\hline
\end{tabular}


nerve stimulation (TENS) therapy; (2) cognitive/ emotion-oriented interventions that include reminiscence therapy, validation therapy, simulated presence therapy (SPT); (3) behavioural management technique and (4) other interventions, such as exercise therapy, pet-therapy and special care unit.

\section{Sensory stimulation interventions}

\section{Shiatsu and acupressure}

Only one SR was identified. Robinson $2011^{44}$ (AMSTAR $=7$ ) investigated the evidence available for shiatsu and acupressure in BPSD. Shiatsu is a form of complementary medicine primarily developed in Japan, which employs gentle manipulations, stretches and pressure with the fingers, elbows, knees and feet. Acupressure is similar, but exerts pressure for longer on specific meridian points according to traditional Chinese medicine or acupoints of the human body in order to 'balance energy fields'.

The authors identified 40 RCTs, 8 controlled clinical trials, 5 crossover trials, 6 within-participants studies, 1 observational study, 10 uncontrolled studies and 1 prospective study. Only one randomised trial ( $\mathrm{n}=133$ participants) using acupressure in dementia participants was relevant for our assessment. ${ }^{45}$ The authors reported that agitation, aggression and physically non-aggressive behaviour all declined significantly in demented participants.

\section{Aromatherapy}

Aromatherapy is proposed as a complementary intervention, to treat a wide-range of health problems, including lack of sleep and behavioural symptoms for people with dementia. ${ }^{46}$ Aromatherapy is based on the use of plant products or aromatic plant oils to produce essential oils and blends of aromatic compounds. Aromatherapy can be delivered through massage or topical application, inhalation and water immersion.

Our systematic search identified three SRs that considered aromatherapy as an intervention to treat agitated behaviours and other outcomes in patients with dementia. The AMSTAR scores ranged from 6 to 8 across the reviews. The range of included primary studies varied from 4 to $13 .{ }^{29} 4748$

The most recent SR was a Cochrane review, ${ }^{48}$ which had the highest AMSTAR quality score (8). The review included only randomised trials and launched its last search strategy in January 2013. Seven studies with 428 participants were identified. The types of interventions included lavender-based (four studies ${ }^{49-52}$ ), Melissabased (two studies ${ }^{53}{ }^{54}$ ) and lemon balm oil (1 study) aromatherapy. However, only two of these had usable data for pooling. The first study $(\mathrm{n}=71)$ reported a favourable treatment effect on measures of agitation (MD $-11.1,95 \%$ CI -19.9 to -2.2 ) and behavioural symptoms (MD -15.8, 95\% CI -24.4 to -7.2), whereas the second trial $(n=63)$ did not detect any difference in agitation (MD $0.00,95 \%$ CI -1.36 to 1.36 ) or behavioural symptoms ( $\mathrm{n}=63$, MD $2.80,95 \%$ CI -5.84 to 11.44 ). The review authors remarked that the published studies used different scales to assess the behavioural symptoms and were limited in sample size and methodological quality, particularly because of selective reporting bias.

The second review by Seitz $e t a l^{29}$ consisted of any nonpharmacological interventions, including aromatherapy, to treat outcomes relevant to patients with dementia. The review reported data in a narrative way and cited only one study of aromatherapy, ${ }^{53}$ which was also included in the Cochrane review above. ${ }^{48}$ The review received an AMSTAR score of 6 .

The third study was a review by Fung et $a l^{47}$ which considered only aromatherapy as a non-pharmacological intervention. The review was judged to have moderate methodological quality (AMSTAR score=6). After performing a comprehensive search in several electronic databases, 11 studies were identified, with a total of 405 patients in different settings, including long-term care (LTC) homes, clinical centres and general and old age psychiatry. In addition to the trials included in the above cited Cochrane review, the review by Fung et $a l^{47}$ included one randomised tria ${ }^{55}$ which was excluded in the Cochrane review because the route of administration was not reported and there was no mention of the type of the aromatherapy, in addition to five controlled clinical trials. ${ }^{56-60}$ Moreover, the Fung et al review ${ }^{47}$ did not include the two trials ${ }^{495161}$ that were evaluated in the Cochrane review. The controlled clinical trials could not be included in a meta-analysis because of heterogeneity. The review highlighted the methodological limitations of the studies and reported promising results of aromatherapy. Online supplementary etable 1 describes the type of interventions, the outcomes and the results of the primary studies included in the aromatherapy reviews.

\section{Massage therapy}

Massage and touch therapy have been proposed as nonpharmacological interventions to be used in dementia to offset manifestations of cognitive decline and behavioural disturbances, including related psychological problems, such as depression and anxiety, and to improve quality of life. ${ }^{62}$

Two reviews were identified. The first was a Cochrane review $^{63}$ that was included in the review by O'Neil et al. ${ }^{31}$ This review assessed the efficacy of massage and touch therapy for the treatment of BPSD. Its last search strategy was launched in 2006. The aim of the overview was to evaluate the effects of a range of massage and touch therapies on conditions associated with dementia, such as anxiety, agitated behaviour and depression, to identify any adverse effects and to provide recommendations for future trials. The review considered only randomised trials. The primary outcome measures were changes in the frequency and severity of various types of agitated behaviour, as observed by staff or investigators (shortterm and long-term using any rating method), and the 
emotional well-being and the quality of life of the patients (rated by staff, investigators and/or patients themselves using any method).

Remington (2002) ${ }^{64}$ assessed the effect of music and massage in 68 nursing home residents with dementia (AD, multi-infarct dementia or senile dementia). The participants were randomly allocated into four groups: calming music, hand massage, simultaneous calming music and hand massage and no intervention. The intervention lasted $10 \mathrm{~min}$ and was given to each patient once.

The efficacy of treatment on 'agitation level' was evaluated with a modified version of the CMAI administered by trained research assistants who were blinded to treatment allocation when possible. The method of randomisation was unclear and to conceal allocation, sealed envelopes, without further explanation, were used. However, patients could have been excluded after allocation (if they had a CMAI score of 0 at baseline) and consequently the study was considered to have high risk of selection bias.

The trial found that agitated behaviour decreased, more so in the group receiving hand massage than in the group receiving no treatment. This treatment effect was consistently found, compared to baseline, for measurements taken during treatment, immediately after treatment and 1-hour after treatment, and it was practically identical among the three groups receiving treatment (hand massage, calming music or both). The mean agitation score was in favour of massage therapy immediately after treatment (MD 7.83 (4.30 to 11.36)) and 1-hour after treatment (MD 12.12 (6.58 to 17.66)).

The second review by Moyle $e t a l^{65}$ conducted a search in 10 databases in October 2011. The authors identified 13 studies that evaluated massage therapy for the treatment of behavioural disturbances in patients with dementia, but only one study with a high methodological score, using the Validity Rating Tool, was identified. The included study, performed by HollidayWelsh, ${ }^{66}$ was a prospective before-after study in which 52 participants (39 women and 13 men; mean age 90 years) from two skilled nursing facilities in Northeastern Minnesota, USA, were enrolled. Patients were cognitively impaired and had a history of agitated behaviour confirmed by the facility staff. The intervention consisted of a 10-min to 15-min massage of the upper extremities (including the head, shoulders and hands), undertaken by a physical therapy assistant, during a 1-hour period identified by caregivers as the time the participant was usually most agitated (individualised for each participant). The outcomes of interest were assessed with a scale that used the five behavioural symptoms from the minimum data set; (1) wandering; (2) verbally abusive behavioural symptoms; (3) physically abusive behavioural symptoms; (4) socially inappropriate/disruptive behaviour and (5) resistance to care.

Methodologically, the study was considered at high risk of selection and performance bias given the study design and the nature of the intervention. In addition, it was unclear whether the outcome assessor was blinded. Massage therapy was significantly associated with improvement for four of the five outcomes examined, including wandering $(0.38$ vs $0.16, \mathrm{p}<0.001)$, verbally agitated behavioural symptoms $(0.59$ vs $0.49, \mathrm{p}=0.002)$, physically agitated behavioural symptoms $(0.82$ vs 0.40 , $\mathrm{p}<0.001)$ and resistance to care $(0.10$ vs $0.09, \mathrm{p}=0.022)$. Online supplementary etable 2 describes the type of interventions, the outcomes and the results of the primary studies included in the massage therapy reviews.

\section{Light therapy}

Rest-activity and sleep-wake cycles are controlled by the endogenous circadian rhythm generated by the suprachiasmatic nucleus (SCN) of the hypothalamus. Degenerative changes in the SCN appear to be a biological cause of circadian rhythm disturbances in people with dementia. In addition to the internal regulatory loss, older people (especially those with dementia) experience a reduction in sensory input, due to less visual sensitivity to light and less exposure to bright environmental light. Evidence suggests that circadian rhythm disturbances may be reversed by stimulation of the SCN with light. ${ }^{67}$

Four reviews considered the use of bright light therapy to treat behavioural problems in patients with dementia.

The first was a Cochrane review ${ }^{67}($ AMSTAR=10) with the aim of evaluating the effectiveness of light therapy to improve cognition, activities of daily living (ADLs), sleep, challenging behaviour and psychiatric disturbances associated with dementia. The search strategy was launched in January 2014. The included studies were randomised trials that compared any bright light therapy, including dim red light or dim, low-frequency blinking light $<300$ lux, to usual care. The primary outcome measures included cognition (global or single domain, eg, memory), ADLs, sleep-wake disturbances, challenging behaviour (eg, agitation), psychiatric disturbances (eg, depression) and adverse effects. Secondary outcomes were rates of institutionalisation and overall cost of care. The authors identified 11 studies, but stated that three of the studies could not be included in the analyses either because the data were insufficient or could not be retrieved from the trial authors. Only four of the included studies considered challenging behaviour as an outcome, but the sample sizes were limited and the outcome measures were not the same across the studies. ${ }^{68-71}$ A meta-analysis of challenging behaviour, however, was performed and no substantial heterogeneity was found, although the results were not statistically in favour of bright light therapy.

The second review aimed to identify which nonpharmacological interventions were most effective for BPSD in LTC. ${ }^{29}$ Only two studies ${ }^{68} 69$ were included in the review (which were already included in the Forbes review $^{67}$ ), but were not assessed in detail. The review received four points in the AMSTAR rating system. 
The third review ${ }^{72}$ aimed to assess the role of physical environment in supporting person-centred dining in LTC. Only one study that evaluated the effect of ambient bright light in activity and dining areas among institutionalised people with dementia was identified. ${ }^{73}$ This study was not included in the previous two reviews.

The fourth review ${ }^{74}$ that addressed the effectiveness of environment-based interventions for people with $\mathrm{AD}$ or dementia identified a cluster-unit crossover trial. ${ }^{75}$ The trial was conducted in two geriatric units in a state-operated psychiatric hospital and in a dementia-specific residential care facility in Oregon, USA, and enrolled 66 older adults with dementia to evaluate the effectiveness of ambient bright light therapy, delivered through a high-intensity, low-glare lighting system installed in the public areas of study units at both sites, at reducing depressive symptoms. Each lighting condition was provided for multiple 3-week periods in a predetermined sequence. The CSDD was used to assess depressive symptoms. Results did not support the use of ambient bright light therapy as a treatment for depressive symptoms in people with dementia. ${ }^{75}$ Online supplementary etable 3 describes the type of interventions, the outcomes and the results of the primary studies included in the light therapy reviews.

\section{Sensory garden and horticultural activities}

Whear $2014^{76}$ (AMSTAR=7) investigated the impact of gardens and horticultural therapy on the mental and physical well-being of residents with dementia, in nursing homes and specialised dementia care facilities. This approach uses either 'sensory' gardens to stimulate the five senses (sight, vision, hearing, smell and touch), or plants and plant-related activities to improve wellbeing (horticultural therapy or therapeutic horticulture). Eighteen studies were identified: ten were quantitative studies (two RCTs ( $\mathrm{n}=34$ ), six pre-post studies, one crossover study, one prospective cohort study), seven qualitative and one used mixed methods. In one of the RCTs, ${ }^{77}$ there was a non-statistically significant decline in verbal and physical aggression and non-verbal aggression, and total CMAI score (Online supplementary etable 4).

Gonzalez $e t a l^{78}$ (AMSTAR=3) examined the effects of sensory garden and horticultural activities in dementia care. Sixteen studies were identified, including 2 RCTs $(n=149)$, one of which was cluster randomised, 11 pre-post studies, 2 case studies and 1 survey. In the smaller of the two RCTs, ${ }^{79}$ verbal agitation significantly decreased in the outdoor horticultural group compared to the indoor horticultural group, while in the larger trial, the effect of participants in the horticultural group did not differ from the traditional activity group. (Connell et $a l^{79}$ was included in both SRs. ${ }^{76}{ }^{78}$ )

Online supplementary etable 4 describes the type of interventions, the outcomes and the results of the primary studies included in the sensory garden and horticultural activities reviews.
Music and dance therapy

Music therapy is the application of music and/or its elements (melody, rhythm, harmony, sound) by a qualified musical therapist, in order to support and stimulate various aspects of cognitive, emotional, social and physical needs, such as expression, communication, learning and forming relationships. Participants can passively listen to music or actively participate by singing, playing an instrument or moving. Dance therapy is a psychotherapeutic intervention that uses movement to 'further the emotional, cognitive, physical and social integration of the individual'. 80

Six SRs that evaluated music therapy, ${ }^{29}{ }^{81-85}$ and one review that assessed live singing to people affected with dementia, ${ }^{80}$ were identified.

The number of included primary studies in the reviews varied from 3 to 18 , and the AMSTAR scores of the reviews ranged from 2 to 7 .

The review by Ueda $2013^{82}$ received the highest score $($ AMSTAR $=7)$ and included nine randomised trials and nine controlled clinical trials that evaluated one music-related experience or a combination of music-related experiences, such as singing, listening, performing, rhythmic exercising and improvising. Uncontrolled before-and-after studies and case studies were excluded.

Participants were allocated to music therapy (mean of $36 \mathrm{~min} /$ day, 2-3 days/week for 10 weeks (range 1 day to 11 months)) or usual care for BPSD assessment. The music therapy comprised listening, ${ }^{86-93}$ moving/ dancing, ${ }^{86} 8889$ 94-97 singing/playing a musical instrument $^{86} 88 \quad 899293959698-102$ and in some occasion was administered in combination with exercise ${ }^{103}$ and reminiscence therapy. ${ }^{89} 99101$

Music therapy was effective in reducing behavioural symptoms (6 RCTs+5 CTs; 397 participants) (SMD= $-0.49(95 \%$ CI -0.82 to -0.17$)$ ), despite a moderate and statistically significant heterogeneity $\left(\mathrm{I}^{2}=58 \%\right.$, $\mathrm{p}=0.009$ ). The same intervention achieved a statistically significant reduction on depression (4 RCTs +5 CTs; 250 participants $) \quad(\mathrm{SMD}=-0.32 \quad(95 \%$ CI -0.68 to $\left.-0.04) ; \mathrm{I}^{2}=44 \%, \mathrm{p}=0.08\right)$ and anxiety (SMD $-0.64,95 \%$ CI -1.05 to $-0.24 ; \quad \mathrm{I}^{2}=55 \%$; eight studies; 258 participants).

Whear $e t a l^{85}$ investigated the effectiveness of mealtime interventions, including music, on BPSD in people with dementia in residential nursing homes or care homes. Eleven studies were identified: one controlled trial, three before/after studies and seven repeated measure time series studies. The results of the studies were described narratively. One before/after study with 22 participants found that music played at mealtime improved physical and verbal, aggressive and nonaggressive, behaviour using the CMAI.

Seitz et $a l^{29}$ (AMSTAR=6) identified 40 RCTs of nonpharmacological interventions, of which 3 studies with 133 participants ${ }^{96} 97{ }^{104}$ evaluated music therapy for BPSD of dementia in LTC facilities. Owing to the heterogeneity of the studies (study design, patient populations, 
interventions, treatment duration and outcomes measured), the authors did not perform a meta-analysis. The behavioural outcome was measured either with a modified CMAI, Behavioural Pathology in Alzheimer's Disease Rating Scale (BEHAVE-AD) or the NPI. In one study, the music therapy was performed with movement, in a group, for $30 \mathrm{~min}$, twice/week for 4 weeks. ${ }^{97}$ In a second study, the music intervention lasted $30 \mathrm{~min}, 3$ times/week for 6 weeks. ${ }^{104}$ And in a third trial, the duration and frequency of individual sessions were not specified, but the therapy lasted 14 weeks. ${ }^{96}$ Two of the three studies employing music found a statistically significant difference between treatment and control groups, but all three were at risk of randomisation bias and two had unclear bias of incomplete outcome data. All the studies were included in Ueda's review. ${ }^{82}$

The review by McDermott et $a l^{81} \quad($ AMSTAR $=4)$ searched MEDLINE, EMBASE, PsycINFO, CINAHL, the Cochrane Library, Web of Science, Journal of Music Therapy and Nordic Journal of Music Therapy and identified 18 studies of which 6 were RCTs (the remaining were non-randomised controlled studies $(n=4)$, before-andafter studies $(n=5)$ and qualitative and mixed-method studies $(n=3))$. Two trials ${ }^{96}{ }^{100}$ and the case-control study ${ }^{104}$ were already included in the reviews described above. $^{29}{ }^{82}$ Three RCTs ( $=165$ ), two of which were carried out by the same group, measured BPSD using either the NPI or BEHAVE-AD. In one trial, the music therapy (patients and music therapist play musical instruments to express emotions and interact) was performed for $30 \mathrm{~min}, 3$ times/week for 1-month, followed by a 1-month interruption, over 6 months (Raglio 2010). In another study by the same group, the music therapy (singing and body movement with music to stimulate communication) was administered for $30 \mathrm{~min}, 30$ times over 16 weeks. ${ }^{96}$ In the third trial, the therapy was executed for $30 \mathrm{~min}, 3$ times/week for 6 weeks (Svansdottir 2006). McDermott et al concluded that evidence for reduction of behavioural disturbance was consistent, but there were no high-quality longitudinal studies that demonstrated long-term benefits of music therapy. Of note, five of the RCTs included in the review were not included in the review by Ueda et $_{a l}{ }^{82}$

Unlike the previous review, Vasionyte and Madison ${ }^{83}$ (AMSTAR $=4$ ) provided a meta-analysis of the effects of music interventions (median $=8$ weeks; range $2-53$ weeks) in patients with dementia, differentiating between different types of interventions (listening, active music therapy, recorded music, live music, selected music, individualised music, classical/relaxation music, popular/native music and group and individual interventions). This SR included 18 studies comprised of 6 RCTs, ${ }^{87} 90 \quad 105-1086$ CCTs ${ }^{88} 91 \quad 98 \quad 102109$ and 6 pre-post-test studies. The outcomes evaluated were behaviour (measured with the CMAI, NPI-Q, Multidimensional Observation Scale for Elderly Participants (MOSES), an agitation checklist or a behavioural chart), affect, cognition and physiology. There was no statistically significant effect on behaviour (effect size (ES) $1.16,95 \%$ CI -0.65 to $2.98 ; 8$ studies, $\mathrm{n}=217$ ) or affect (ES $0.38,95 \%$ CI -0.56 to $1.32 ; 6$ studies, $\mathrm{n}=109$ ), while cognition (ES $1.56,95 \%$ CI 1.11 to $2.01 ; 4$ studies, $\mathrm{n}=63$ ) and physiology (ES $0.72,95 \%$ CI 0.36 to $1.08 ; 4$ studies, $n=88$ ) were affected. Three of the RCTs, and four of the controlled trials, in this review, were also included in Ueda et $_{\text {al. }}{ }^{82}$

The review by Wall and Duffy ${ }^{84}$ included 13 studies that were presented narratively. The review was of low quality (AMSTAR score 2).

The review by Chatterton $e t a l^{80}$ evaluated the efficacy of 'live' singing to people with dementia for cognitive, behavioural, physiological and social outcomes. The study received an AMSTAR score of 1 .

An additional $\mathrm{SR}^{72}$ that aimed to assess the role of the physical environment in supporting person-centred dining in LTC identified four non-randomised studies, with different designs, that evaluated the effect of music on the incidence of agitated behaviours during mealtimes, among older adults with dementia, residing in special care units (SCUs). ${ }^{110-113}$ The results of these studies showed that playing music during mealtime reduced the incidence of agitated behaviour.

Online supplementary etable $5 \mathrm{a}$ describes the type of interventions, the outcomes and the results of the primary studies included in the music therapy reviews.

\section{Dance therapy}

Two reviews evaluated dance therapy in patients with dementia. ${ }^{114} 115$ The first review's objective was to evaluate the evidence concerning dancing interventions in physical and mental illnesses compared to other types of interventions or non-specific interventions. ${ }^{115}$ The review received 3 points in the AMSTAR scoring system and identified 13 small studies reporting results from 11 randomised trials of which only one considered patients with dementia. The trial that considered participants with dementia included 29 participants (mean age 79 years, SD $7.7 ; 75 \%$ women) in a nursing home and evaluated the efficacy of dance and movement therapy delivered in nine sessions, lasting 30 to $45 \mathrm{~min}$ each, once-a-week. ${ }^{116}$ The outcome measures included the word list savings score, the Clock drawing test (for visual spatial ability), the Cookie Theft picture description task from the Boston Diagnostic Aphasia test and the Nurses' Observation Scale for Geriatric Patients (NOSGER). The results did not show any important differences in favour of dance therapy.

The second SR aimed to evaluate the effects of dance (movement) therapy and ballroom dancing, compared to usual care, for adults with physical and mental illnesses. ${ }^{114}$ The review received only one point on the AMSTAR Scale and identified only one study that investigated the intervention in a population affected by dementia ${ }^{116}$ and which was also included in the review above. 
Snoezelen multisensory stimulation therapy

Snoezelen multisensory stimulation therapy (SMST) comprises multiple stimuli and is aimed at stimulating the primary senses of sight, hearing, touch, taste and smell. The intervention is provided in specially designed rooms, which provide diverse sensory-stimulating effects/material including music, aroma, bubble tubes, fibre optic sprays and moving shapes projected across walls. SMST was investigated by two reviews. ${ }^{29} 31$

The first was an overview of reviews, ${ }^{31}$ and its evidence for SMST was based on a Cochrane review that included three studies. ${ }^{117}$ The inclusion criterion was any randomised trial that assessed the efficacy of SMST and/or multisensory stimulation to treat people over 60 years of age suffering from dementia. The outcomes of interest included behaviour, mood, cognition, physiological indices and client-carer communication, as well as shortterm effects measured during the sessions or postsession, and longer term benefits measured postintervention and at follow-up.

The three included primary studies evaluated a total of 311 patients with dementia, aged 60 or older. The first was a randomised trial ${ }^{118}$ that compared eight standardised multisensory programmes with eight standardised activity sessions. Both programmes were implemented on a one-to-one basis, twice-a-week, with each session lasting $30 \mathrm{~min}$. Fifty participants (25 women, mean age 78$)$ with a diagnosis of $\mathrm{AD}(\mathrm{N}=33)$, vascular dementia $(\mathrm{N}=7)$ or a mixed diagnosis $(\mathrm{N}=10)$ were enrolled. The objectives of the trial were the immediate effects of SMST on the behaviours of older people with dementia, the carryover effects of SMST on mood and behaviour to day-hospitals and home environments and the maintenance effects of SMST on mood, behaviour and cognition over time. The effects of SMST on behaviour were measured by INTERACT. ${ }^{119}$ The generalisation effects were measured by three outcome measures: the carryover effect of day-hospitals was measured with the General Behaviour and Community Skills subscales of REHAB (Baker 1988); the carryover effect to home, at midintervention and postintervention, was measured with the Behaviour and Mood Disturbance Scale (BMD) and the Behaviour Rating Scale (BRS) of the Clifton Assessment Procedures for the Elderly (CAPE). The maintenance effect (at the 1-month postintervention follow-up) on behaviours and cognition were measured by REHAB, BMD, the Cognitive Assessment Scale (CAS) of CAPE and Mini-Mental State Examination (MMSE). No significant effects on any scale of behavioural symptoms were found either immediately after intervention or at 1-month follow-up.

The second study ${ }^{120}$ was a quasi-experimental pre-test and post-test design with cluster randomisation performed at a ward level, which compared a 15-month, 24-hour individualised care plan that was integrated with SMST, with 15-month usual care. The study included 136 participants diagnosed with $\mathrm{AD}$, vascular or mixed dementia from three different countries (UK=94 day patients, the Dutch sample=26 inpatients. Swedish sample $=16$ inpatients). There was a significant group difference in the mean baseline MMSE scores (data from the UK and the Dutch only) between the SMST group (9.4) and the control group (6.7) $(\mathrm{p}=0.01)$. All participants attended eight, 30-min sessions on a one-to-one basis according to their group assignment. The sessions were conducted by the same key workers throughout the study period. The following outcomes measured the short-term effects of SMST on behaviours: (1) INTERACT (22-item) measured behaviours during the sessions; (2) INTERACT (12-item) measured behaviours $10 \mathrm{~min}$ before and $10 \mathrm{~min}$ after the sessions and (3) Behaviour Observation Scale for Intra-mural PsychoGeriatrics (GIP) measured behaviours that were videotaped during the sessions in the Netherlands sample.

The study showed significant effects on two behavioural items of INTERACT during sessions: enjoying oneself $(\mathrm{MD}=-0.74 ; 95 \%$ CI $(-1.29$ to -0.19$) ; \mathrm{z}=2.62$, $\mathrm{p}=0.01)$ and bored/inactive (MD $=-0.56 ; 95 \%$ CI $(-1.11$ to -0.01$) ; \mathrm{z}=1.99, \mathrm{p}=0.05)$. There were no longer term treatment effects of the integrated SMST-care programme on behaviour.

The third study ${ }^{121}{ }^{122}$ assessed the effects of SMST when integrated into 24-hour daily care on nursing home residents with dementia. A total of 125 patients with moderate or severe dementia and care dependency were recruited from six old age psychiatry wards for pre-test. A cluster randomised design was used to assign the wards to either experimental (integrated SMST-care programme) or control (usual activity) conditions. Twelve old age psychiatry wards in six nursing homes (out of 19 homes) were recruited to the study. At baseline, 125 participants (woman $79 \%$, mean age 84 ) were recruited and were assigned to experimental or control conditions according to the ward in which they stayed. For the experimental group, participants were given a stimulus-preference screening in 10 weekly one-hour sessions to identify their preferred sensory stimuli. Subsequently, individual SMST-care plans were developed for each participant based on their life history, stimulus preference and discussions from multidisciplinary conferences. Certified nursing assistants (CNAs) used multisensory stimuli in the 24-hour care of the experimental participants. Participants in the control group were provided with individual usual care. A minimum period of 3 months was used for experimental and control conditions.

The short-term effects of the integrated SMST-care programme on behaviours were measured using a modified version of INTERACT, in which six items were deleted and eight new items were added during morning care sessions. The long-term effects of integrated SMST-care programmes on behaviours, mood and interaction were evaluated at the 18-month follow-up using the eight items of GIP for apathy, anxiety and disoriented behaviours, the Dutch version of CMAI for agitated behaviours, physically non-aggressive 
behaviour and verbally agitated behaviours and the Cornell Scale for Depression for depressive symptoms. In terms of behavioural disturbances, when compared to the control, the 24-hour integrated SMST-care programme $^{122}$ showed a significant effect on two behavioural items of INTERACT during sessions: enjoying self $(\mathrm{MD}=-0.74 ; 95 \%$ CI $(-1.29$ to -0.19$) ; \mathrm{z}=2.62, \mathrm{p}=0.01)$ and bored/inactive (MD $=-0.56 ; 95 \%$ CI $(-1.11$ to $-0.01) ; \mathrm{z}=1.99, \mathrm{p}=0.05)$. There were no longer term treatment effects of the integrated SMST-care programme on behaviour. In terms of mood, there were significant improvements in one mood item of INTREACT during sessions: the SMST group was happier and more content than the control group ( $\mathrm{MD}=-0.84 ; 95 \%$ CI $(-1.39$ to -0.29$) ; \mathrm{z}=2.98, \mathrm{p}=0.003)$. There were no significant effects of the 24-hour integrated SMST at postintervention. The fourth review scored 6 in the AMSTAR evaluation and investigated different nonpharmacological interventions including SMST for the treatment of BPSD. ${ }^{29}$ The review identified only one study that was included in the above cited review. ${ }^{122}$ Online supplementary etable 6 describes SMST-based interventions, outcomes and results of the primary studies included in the reviews.

\section{Transcutaneous electrical nerve stimulation}

TENS is a simple, non-invasive, non-pharmacological intervention commonly used for pain control ${ }^{123}$ and occasionally for neurological and psychiatric conditions such as drug/alcohol dependency, headaches and depression. ${ }^{31}$ TENS consists of attaching electrodes to the skin and applying an electrical current, whose frequency can vary from low $(<10 \mathrm{~Hz})$ to high $(>50 \mathrm{~Hz})$.

Two reviews were identified. One review that evaluated current treatment options for sleep disturbance in $\mathrm{AD}$ scored 3 in the AMSTAR evaluation. ${ }^{124}$ Different nonpharmacological interventions were considered, including bright light therapy, behavioural and multifaceted interventions (combined increased daytime physical activity and exercise, decreased daytime in-bed time, daily sunlight exposure, structured bedtime routine and decreased night-time noise and light) and TENS. For the latter intervention, only one randomised trial of 19 nursing home residents was identified. The study did not evaluate behavioural outcomes.

A Cochrane review that was included in O'Neil's review ${ }^{31}$ was also considered. ${ }^{125}$ The review was focused only on RCTs that enrolled inpatients and outpatients of any age (with or without caregivers), with a diagnosis of dementia. The outcomes of interest included visual and verbal short-term and long-term memory, semantic verbal fluency, circadian rest-activity rhythm, affect/ depression, level of independent functioning, adverse effects and dropouts due to inefficacy. The review identified and included nine trials that were performed in Japan and the Netherlands. The Dutch studies were performed by the same group of authors. ${ }^{126-131}$ These studies were randomised placebo-controlled trials, and the participants were chosen from a group of 350-500 residents of a residential home for older people. The age range of the participants was $\sim 70$ to mid-90 years and were mostly women $(>80 \%)$. All participants met NINCDS-ADRDA criteria for the clinical diagnosis of probable $\mathrm{AD}$; most participants had early $\mathrm{AD}$, but some had moderate AD. Participants generally had scores of 17 or less on the Hamilton Depression Rating Scale. All included studies used a similar TENS protocol, except the most recent one published in 2002, which addressed cranial electrostimulation.

The remaining three publications were performed by a group of authors from Japan and describe the results of the same study. ${ }^{132}$ The study design was a doubleblind crossover and, in contrast to the Dutch studies, participants were thought to have multiinfarct dementia or $\mathrm{AD}$ and were selected on the basis of irregular sleepwake patterns in conjunction with nocturnal behaviour disorders and/or dementia. Twenty-seven participants completed the study. The intervention used a HESS-10 stimulator with rectangular pulse waveforms at a frequency of $6-80 \mathrm{~Hz}$, a pulse duration of $0.2 \mathrm{~ms}$ maximum, $256 \mu \mathrm{Amps}$ and an amplitude of $6-8 \mathrm{~V}$. The outcomes evaluated were sleep disorder, motivation, behaviour disorder, intelligence, emotion, language, neurological signs, subjective symptoms and activities of daily life. All of these were rated on a five-point scale: absence of the related symptom, 0; mildly disturbed, 1; moderately disturbed, 2; markedly disturbed, 3 and severely disturbed, 4 . Of the nine studies, only three could be included in a meta-analysis for a combined total of 63 participants. Two of these studies were conducted in the Netherlands, and one was conducted in Japan. Results, however, were inconclusive. It should be noted that none of the other studies mentioned adverse effects, although it is unclear if adverse events were monitored.

Online supplementary etable 7 describes TENS-based interventions, outcomes and results of the primary studies included in the reviews.

\section{Cognitive/emotion-oriented interventions Cognitive stimulation}

Cognitive stimulation involves a variety of pleasurable activities, such as word games, puzzles, music, cooking, gardening and discussing past and present events, and is usually carried out by trained personnel with small groups of four to five people. It lasts for $45 \mathrm{~min}$, minimally 2 times/week. It is based on Reality Orientation, which was developed in the 1950s to counteract the confusion and disorientation of older people during hospitalisations. Seven reviews were identified. ${ }^{133-139}$

Woods $2012^{133}$ (AMSTAR score=10) was a Cochrane review that identified 15 RCTs that used cognitive stimulation for people with dementia. The authors stated that most of the studies were of low quality, but that generally, investigators had taken measures to protect against 
the risk of allocation concealment bias. In a meta-analysis of three trials ${ }^{140-142}$ ( $n=190$ participants), the intervention had no effect on problem behaviours (SMD $-0.14,95 \%$ CI -0.44 to $0.17 ; \mathrm{I}^{2}=0 \%, \mathrm{p}=0.57$ ).

The review by Aguirre et al in 2013 ${ }^{134}$ (AMSTAR score $=5$ ) evaluated the effectiveness of cognitive stimulation in patients with dementia and identified nine RCTs. Three trials that considered behaviour-related outcomes were identified. These trials were already included in Woods's review ${ }^{133}$ and reached the same conclusion.

Alves et al in $2013^{135}$ (AMSTAR score=4) identified four RCTs of cognitive interventions for $\mathrm{AD}$ patients. Only one trial that measured BPSD as an outcome was identified. The study population was composed of 32 patients with a score between 10 and 24 on the Mini Mental State Examination, no history of antidepressant medication and a total NPI score $>5$ points arising from at least 2 domains of behaviour. The cognitive stimulation intervention was administered individually and focused on a set of tasks requiring executive functions and working memory. The study found a statistically significant reduction of BPSD (MD -2.06 ; 95\% CI -2.91 to $-1.21)$.

The study of Carrion et al in 2013 ${ }^{136}$ (AMSTAR score $=4$ ) found 17 RCTs of cognition-oriented interventions (reality orientation and skills training) for dementia sufferers. Challenging behaviour was evaluated in only two trials $(n=156$ and $n=44$, respectively) that employed the two categories of cognitive interventions, using the NPI and the Revised Memory and Behaviour Problems Checklist. In both RCTs, the intervention group had a smaller increase in change from baseline compared to the control group. Owing to the heterogeneity among the studies, the authors decided a meta-analysis was inappropriate.

Yu $2009^{137}$ (AMSTAR=3) included 15 studies (9 RCTs, 5 CCTs and 1 before-after study), in addition to 5 case studies and 3 undefined studies, all of which investigated different types of cognitive interventions for $\mathrm{AD}$ and dementia. The only study, a CCT $(n=32$ with early-stage $\mathrm{AD})$, that evaluated the effect of cognitive stimulation on behavioural disturbances, showed larger improvement than the cognitive training group.

Olazarán et al in $2010^{138}$ (AMSTAR=4) identified 179 RCTs of diverse types of non-pharmacological interventions for $\mathrm{AD}$ patients and examined problem behaviour, mood, QoL, cognition, ADLs, mechanical restraint and institutionalisation of patients and mood, psychological well-being and QoL of CGs. The authors performed a meta-analysis of three low-quality RCTs to determine the effect of cognitive stimulation on problem behaviour and mood. There was a non-statistically significant reduction in problem behaviour (group session cognitive stimulation ( $\mathrm{ES}=0.61 ; 95 \%$ CI 0.09 to 1.12$)$ ). The primary study by Baines et $a l^{140}$ was included in the Woods ${ }^{133}$ review above, while the study by Robichaud $e t a l^{143}$ was included in the review by $\mathrm{Kim}^{144}$ which examined behaviour management techniques described below.
Thirty-three RCTs, employing cognitive interventions for cognitively impaired individuals (dementia and mild cognitive impairment), were identified in Kurz et $a l^{145}$ (AMSTAR score $=2$ ). Twelve of these trials examined behavioural disturbances, but only three studies found a significant effect of the intervention.

Zientz et $a l^{139}$ (AMSTAR score=2) identified three studies (two RCTs and one RCT or CCT; n=124 participants) of caregiver-administered cognitive stimulation for individuals with $\mathrm{AD}$. One of the randomised trials $(n=16)$ found that individuals who received the intervention displayed fewer behavioural problems compared to those who had not been given the intervention.

Online supplementary etable 8 describes cognitive stimulation-based interventions, outcomes and results of the primary studies included in the reviews.

\section{Reminiscence therapy}

Reminiscence therapy is a non-pharmacological intervention that involves the discussion of past experiences, events and activities with family members or other groups of people. The intervention uses materials such as photographs, books, old newspapers and familiar items from the past to inspire reminiscences and facilitate people to share and value their experiences. Three reviews assessed reminiscence therapy as a nonpharmacological intervention to treat agitated behaviour in patients with dementia. ${ }^{29} 146147$

The first review ${ }^{29}$ received the highest score (AMSTAR score of 6) and considered all non-pharmacological interventions to treat relevant outcomes in patients with dementia. The review identified two small studies involving a total of 107 patients ${ }^{148} 149$ performed in care facilities. The NPI and the Clifton Assessment Procedures for the Elderly-Behavioural Rating Scale (CAPE-BRS) were used to measure BPSD. Seitz et $a t^{29}$ reported that this outcome was unaffected in one study, ${ }^{149}$ while the effect of the intervention was unclear in the other study. ${ }^{148}$

The second review ${ }^{147}$ was focused only on reminiscence therapy as a sole treatment of behavioural outcomes for patients with dementia. The review was of low methodological quality (AMSTAR score $=3$ ). The results were presented in a narrative synthesis. The review included five trials with a before-after design, containing 258 patients affected by dementia. The studies considered different interventions. Two studies (one with 31 participants (Haight 2006) ${ }^{150}$ and the other with 17 participants (Morgan 2010 $0^{151}$ )) assessed a life review or story approach and found significant improvements in depression, communication, positive mood and cognition. The third study (101 participants (Lai 2004 $\left.{ }^{152}\right)$ ) evaluated specific reminiscence, which produced a life-story book using personalised triggers for each person's life history. No significant differences were observed between groups except for outcomes such as well-being and social engagement. The remaining two trials (involving 73 participants ${ }^{153}$ ) and 36 participants ${ }^{154}$ ) evaluated individual reminiscence approaches. 
One study used six weekly sessions, which focused on a particular life phase, such as childhood or family life, while the other study used a basket of visual and auditory activities, based on five themes, such as musical instruments, designed to stimulate reminiscence. No significant differences were observed between the groups in terms of behavioural outcomes.

The third review ${ }^{146}$ focused on whether reminiscence therapy could alleviate depressive symptoms in adults with dementia, but its methodological quality was extremely low (AMSTAR score $=1$ ). Four primary studies with a pre-post-test design were included and were described individually, three of which were randomised trials and one of which comprised a single group.

Online supplementary etable 9 describes reminiscence therapy interventions, outcomes and results of the primary studies included in the reviews.

\section{Validation therapy}

Validation therapy is based on the general principle of the acceptance of the reality and personal truth of another person's experience and incorporates a range of specific techniques. Validation therapy is intended to give the individual an opportunity to resolve unfinished conflicts by encouraging and validating the expression of feelings. The specific interventions and techniques are based on a synthesis of behavioural and psychotherapeutic methods. The approach can be used as a structured therapeutic activity in a group setting, usually lasting several weeks, or it can be conducted individually as part of an ongoing approach to facilitate communication as a supplement to group work. The validation therapy techniques comprised non-threatening, simple concrete words; speaking in a clear, low and empathic tone of voice; rephrasing and paraphrasing unclear verbal communication; responding to meanings through explicit and implicit verbal and non-verbal communication and mirroring verbal and non-verbal communication.

One Cochrane review that evaluated the effectiveness of validation therapy to reduce BPSD was identified (AMSTAR score $=7$ ). ${ }^{155}$ The review included only randomised trials of participants over 65 years of age, diagnosed with Alzheimer's disease, dementia or other forms of cognitive impairment, according to ICD 10, DSM IV or comparable criteria. The outcomes of interest were cognition, behaviour, emotional state and activities of daily living. The review, updated in 2005, included three randomised trials ( $\mathrm{n}=155$ participants). ${ }^{156-158}$ Another $\mathrm{SR}^{159}$ that evaluated the effective characteristics of residential LTC settings for people with dementia identified one trial ${ }^{158}$ that was included in the Cochrane review. ${ }^{155}$

\section{Primary studies}

Among the primary studies, the first study ${ }^{156}$ (n=31) was performed in a nursing home and used an intervention
(30 min once-per-week for 6 weeks) that included activities such as discussion of a previously agreed subject, singing and movement, followed by a closing ritual and refreshments. Behaviour was measured with the Behaviour Assessment Tool. The control groups consisted of reminiscence therapy, which followed the guidance of a reality orientation manual (cues such as flannel boards and calendars were used to promote orientation) and usual care. At 6 weeks, validation therapy was associated with a decrease of problem behaviours $(\mathrm{MD}=-5.97,95 \%$ CI -9.43 to $-2.51 ; \mathrm{p}<0.001$; based on an analysis of participants who completed the study).

The second study ${ }^{157}$ enrolled 36 patients with moderate-to-severe disorientation of which 25 had a diagnosis of dementia. The study was performed in a LTC institution in the USA. The validation therapy was performed twice-a-week for 9 months; details of the validation therapy were not given. Agitation was measured using the Minimal Social Behaviour Scale (MSBS; Farina 1957) where a reduction in score indicated improvement. No effects on behaviour were detected.

The last study ${ }^{158}$ was carried out in 'skilled-care nursing homes' in the USA. In this study, patients were included if they had at least a moderate level of dementia (assessed by the Short Portable Mental Status Questionnaire-SPMSQ_-and the Validation Screening Instrument) and displayed problem behaviours, such as physical aggression. Validation therapy (four meetings lasting 30 min per week for 52 weeks) was composed of groups divided into four sessions of 5-10 min each. The first session included introductions, salutations and singing. The second session involved conversation regarding a subject of interest; recalling past events was promoted. The third session comprised an activity programme and singing or poetry. The fourth session involved refreshments and individual goodbyes. Agitation was measured with the CMAI, ${ }^{160}$ carried out as CMAI(N) nurse observed and $\mathrm{CMAI}(\mathrm{O})$ non-participant observed. The authors reported that depression (MOSES) decreased at 12 months (MD $-4.01,95 \%$ CI -7.74 to -0.28 ; $\mathrm{p}=0.04$, based on an analysis of participants (66 out of 88) who completed the study. Online supplementary etable 10 describes validation therapy interventions, outcomes and results of the primary studies included in the reviews.

\section{Simulated presence therapy}

SPT involves the use of video/audiotapes made by family members containing scripted 'telephone conversations' about cherished memories from earlier parts of a person's life, in an effort to stir remote memory, improve behavioural symptoms and enhance the quality of life among people with dementia. ${ }^{161}$ Two SRs were identified. $^{30162}$

The first review was written by only one reviewer and scored 3 on the AMSTAR Scale. The review was aimed at investigating the effectiveness of SPT for challenging 
behaviours in dementia. The review searched PubMed, PsycINFO and the Web of Science, conducted hand searches of relevant articles and considered for inclusion, studies that reported pre-test and post-test, or pre-test and during-test data for SPT for challenging behaviours. The SPT consisted of audio or videotapes prepared by a spouse, family members, the caregiver, a psychologist, a surrogate or researchers. Of the seven included primary studies, only the data from four could be pooled, showing an overall mean effect of 0.70 , with a $95 \%$ CI of 0.38 to 1.02 , but with statistically significant heterogeneity $\left(\mathrm{I}^{2}=71 \%, \mathrm{p}=0.02\right)$.

The second review examined the efficacy of any nonpharmacological intervention (including SPT) to reduce BPSD in patients with dementia. ${ }^{162}$ After searching the databases MEDLINE, CINAHL, PsycINFO, EMBASE, Dissertations International and the Cochrane Database of Systematic Review, from 1974 to May 2008, the review identified only two studies that were included in the Zetteler review above. ${ }^{30}$ Online supplementary etable 11 describes SPT, outcomes and results of the primary studies included in the reviews.

\section{Behavioural management techniques}

There is a multitude of behavioural interventions that constitute behavioural management techniques, which include behavioural or cognitive-behavioural therapy, functional analysis of specific behaviour, individualised behavioural reinforcement strategies, communication training and other therapies such as habit training, progressive muscle relaxation and token economies. These behavioural interventions can be realised either with the patient or by training caregivers to perform the intervention with the patient.

One overview of reviews and four SRs that considered behavioural interventions were identified. The overview of reviews by O'Neil $2011^{31}$ identified three SRs, and after performing additional searches of primary studies, included nine randomised trials. ${ }^{163-171}$ The overview authors' conclusions were in support of behavioural management techniques as effective interventions for behavioural symptoms of dementia although they admitted there were mixed results. In addition, the authors highlighted some concerns regarding the variety of specific interventions and methodological limitations in many studies and advocated additional research with carefully assessed outcomes.

A Health Technology Assessment (HTA) ${ }^{172}$ report that aimed to evaluate the clinical and cost-effectiveness of sensory, psychological and behavioural interventions to manage agitation in older adults with dementia, systematically searched and identified four randomised trials. ${ }^{166} 173-175$ The intervention in all four trials was caregiver-based. The HTA authors concluded that the evidence in favour of the behavioural management techniques was limited.

A Cochrane review ${ }^{176}$ aimed to assess the effects of functional analysis-based interventions for people with dementia (and their caregivers) living in their own home or other settings and identified 18 randomised trials. The development of the intervention was driven by various approaches and theories, including knowledge and/or training approaches, the stress-coping model, the progressively lowered stress threshold model and problem-solving approaches. In addition, the time frame in which the intervention was delivered varied from 9 days to 18 months and the number of sessions used to deliver the intervention varied widely, from 1 to 2 sessions to more than 10 sessions. Of the 18 studies included, ${ }^{164-168} 173 \quad 174 \quad 177-187$ the authors were able to meta-analyse data from 4 trials, ${ }^{178} 180182188$ of which one contained unpublished data. There were no significant reductions in the incidence of challenging behaviours reported postintervention in four family care studies (SMD $0.02,95 \%$ CI -0.13 to $0.17, \mathrm{p}=0.80$, $\mathrm{N}=722$ ).

Among 179 RCTs of diverse types of nonpharmacological interventions for $\mathrm{AD}$ patients, identified by Olazarán 2010 138 (AMSTAR score $=4$ ), the authors performed a meta-analysis of three low quality RCTs of behavioural interventions (analysis and modification of antecedents and consequences of behaviour) and found a statistically significant reduction in problem behaviour ( $\mathrm{ES}=0.57,95 \%$ CI 0.21 to $0.92 ; 3$ trials; $\mathrm{n}=167$ ). The same authors carried out another meta-analysis of four low-quality RCTs of care staff training in behavioural management and found a reduction in problem behaviour ( $\mathrm{ES}=0.22,95 \%$ CI 0.02 to 0.43 ; 4 trials; $\mathrm{n}=370$ ).

Two primary studies examined emotion-oriented care. The first study ${ }^{189}$ was a RCT of NH residents $(n=146$ older residents with $\mathrm{AD}$, mixed $\mathrm{AD}$ and vascular dementia and dementia syndrome; mean age 84 ). The intervention of emotion-oriented care was associated with less anxious behaviour in the group of residents who needed less assistance/care compared to similar residents in the usual care group. The second study ${ }^{190}$ was a cluster randomised study of residential care homes $(\mathrm{n}=16$ homes; $\mathrm{n}=151$ residents). The authors reported that there was no statistically significant effect of the intervention on any behavioural outcome, including behavioural problems. Teri $2000^{174}$ was included in the HTA; ${ }^{172}$ Gormley $2001^{173}$ and Teri $2005^{166}$ were included in the Brodaty 2012 review; ${ }^{191}$ Gonyea $2006^{183}$ was included in reviews in behaviour management techniques and McCallion 1999 and Teri 2005 were included in Eggenberger 2013. ${ }^{192}$

Eggenberger $2013^{192}$ (AMSTAR score=3) aimed to evaluate interventions that were designed to enhance communication or interaction in dementia care, in any setting. Review authors identified 12 studies (7 randomised trials, 2 controlled clinical trials and 3 beforeafter studies) that focused on communication training for staff in institutions and family caregivers at home. In institutional settings, the results on challenging behaviour, of residents with dementia, were not consistent. 
Four studies reported a significant reduction of challenging behaviour. ${ }^{171} 193194$ McCallion et al, ${ }^{171}$ for instance, demonstrated a decrease of physically aggressive behaviour (15.16 (SD 9.81) to 12.21 (SD 8.31), $\mathrm{p}<0.001)$ ) and a reduced mean occurrence of verbally aggressive behaviour in patients with dementia (16.22 (SD 10.31) to 12.88 (SD 8.39), $\mathrm{p}<0.001)$ ). In addition, one trial demonstrated a significant decrease of residents' agitation during care routines $(\mathrm{F}(1.7=5.12, \mathrm{p}<0.05)) .{ }^{194}$ Conversely, three studies reported no effect on challenging behaviour of people with dementia. ${ }^{195-197}$ Only one trial ${ }^{167}$ was included in the Brodaty 2012 review. ${ }^{191}$

Kim et $a l^{144}$ conducted a review to assess the effectiveness of occupational therapy on behavioural problems and depression in patients with dementia. MEDLINE, CINAHL, ProQuest and The Cochrane Library were searched up to the end of March 2011. The AMSTAR score was 7 . The authors defined occupational therapy as an application of 'activity analysis, caregiver training, sensory stimulation, behaviour control skill teaching, physical and social environmental modification, cognitive training, and purposeful activity'. The review identified nine randomised trials with a total of 751 participants. On the basis of the type of intervention, the authors categorised four studies ${ }^{118} \quad 120 \quad 143 \quad 198$ as sensory stimulation, three studies ${ }^{198-200}$ as functional task activities and two studies ${ }^{200} 201$ as environmental modification. The authors performed a meta-analysis of the trials with occupational therapy-based sensory stimulation and found an ES of 0.32 (95\% CI 0.04 to 0.59; 250 participants; no significant heterogeneity). No significant effect was detected for OT-based functional task activities $(0.15,95 \%$ CI -0.17 to $0.47 ; 203$ participants) or environmental modification $(0.13,95 \%$ CI -0.09 to 0.36 ; 298 participants).

\section{Primary studies}

Overall 22 trials were evaluated in the 6 reviews that were included. Except for one study performed in Taiwan, all the studies were carried out in Europe, the USA and Australia. Thirteen studies were performed in family care settings. ${ }^{164} 167168173174178180{ }^{182-187}$ Three studies with a total of 740 residents were conducted in care homes. ${ }^{165} 179181$ Finally, one study was located in an assisted living setting ${ }^{166}$ and the other in a hospital setting. ${ }^{177}$

Characteristics of the interventions varied greatly across the trials. Fifteen trials were focused on enhancing communication skills in family and formal caregivers. Eighteen trials focused on functional activity of which four were described as a behavioural management intervention. The intervention in one trial involved caregiver training on verbal or non-verbal communication focused on activities of daily living. Another trial was dedicated to teaching participants the basic technique for progressive muscle relaxation. ${ }^{170}$ Time delivery of the intervention also varied widely. However, as noted by Moniz-Cook, the intervention delivery was determined by setting: the interventions in care homes were provided weekly and lasted for 6 months. ${ }^{176}$ In one family care study, the intervention was provided in just 4 sessions over 8 weeks. ${ }^{173}$ Follow-up data varied from a few weeks to 24 months.

\section{Setting-based description}

Family care: In this setting, family caregivers assisted people with dementia at home, with or without support from formal caregivers, healthcare workers and adult day care centres. Thirteen trials were conducted in a family care setting. ${ }^{164} \quad 166 \quad 168 \quad 173 \quad 174 \quad 176 \quad 178 \begin{array}{lllll}180 & 182-185\end{array}$ 187200201

Six of these trials investigated an intervention that was focused on enhancing communication skills of the caregiver. The duration of the intervention ranged from 3 weeks ${ }^{184}$ to 12 months. ${ }^{178}$ The number of weekly sessions administered were, according to a classification proposed by Moniz-Cook 2012, ${ }^{176}$ high (>10 session) in three trials, ${ }^{164} 178180185$ moderate-high (6-10 sessions) in one trial, ${ }^{185}$ moderate ( 3 to 5 sessions) in one trial ${ }^{182}$ and minimal ( 1 to 2 sessions) in one trial. ${ }^{184}$ The participants who delivered the interventions varied from trial to trial: occupational therapists; ${ }^{182}$ trained nurses or social workers; ${ }^{180}$ professionals specialised in the REACH programme; ${ }^{178}$ healthcare professionals supervised by an old age psychologist; ${ }^{164}$ psychologists ${ }^{185}$ or trial investigator together with an experienced nurse. ${ }^{184}$

Of the 13 trials in the family care setting, 4 investigated a behavioural intervention that was focused on providing support to the caregiver. The interventions lasted from 5 weeks ${ }^{183}$ to 18 months, ${ }^{186}$ with the number of sessions that varied from $4^{186}$ to 8 sessions, ${ }^{187}$ with home visits ${ }^{176} 187$ and associated with or followed by telephone contacts. ${ }^{166168}$ Overall, the intervention dosage was high for three trials, ${ }^{166} 168176$ medium-high in one trial $^{187}$ and moderate in one trial. ${ }^{183}$ The interventions were delivered by different healthcare experts: community mental health nurses; ${ }^{176}$ therapists; ${ }^{187}$ occupational therapists; ${ }^{168}$ community consultants trained by an old age psychologist. ${ }^{166}$

The remaining two trials evaluated behavioural management techniques. Teri $2000^{174}$ compared the intervention consisting of eight weekly and three biweekly sessions (high-intensity intervention) with pharmacological interventions or placebo. The intervention was provided by a therapist with a master's degree and 1-year clinical experience, but was not reported in detail. The postintervention evaluation started at 4 months, and the follow-up lasted beyond 12 months. The second study ${ }^{173}$ did not completely describe the intervention for behavioural management. The intervention was delivered in four sessions (moderate intensity) over 8 weeks by the trial investigator.

In terms of results, no statistically significant change in the incidence of challenging behaviours was observed in any of the studies. Moniz-Cook 2012 meta-analysed data of four studies $(\mathrm{N}=722)$, but did not find any difference 
among the groups (SMD 0.02, 95\% CI -0.13 to 0.17 , $\left.\mathrm{p}=0.80 ; \mathrm{I}^{2}=0 \%\right) .{ }^{168} 178180182$ At follow-up of 6 months, two studies did not show any significant effect of behavioural management techniques. ${ }^{168} 180$

When the frequency of challenging behaviours was examined, none of the studies detected a significant difference even when a meta-analysis, using the data from 10 studies, was performed (SMD $-0.05,95 \%$ CI -0.17 to $0.07)$.

Assisted living: In this setting, people with dementia lived in a residence, did not require full-time nursing care, but needed assistance with some ADLs, such as bathing, dressing and eating. Family members could still act as intermittent caregivers during visits by providing different types of support for ADLs, instrumental ADLs (eg, laundry washing, room cleaning, transportation to a doctor's office), socioemotional support (eg, talking, reminiscing, socialising), monitoring care provision or advocating. ${ }^{202}$ One study evaluated a behavioural management intervention to improve caregiver training to manage residents with dementia. ${ }^{166}$ The intervention intensity was medium-high, delivered by a clinical psychologist and graduate nursing students who performed two half-day group workshops and four individualised sessions with a follow-up 2 months after the termination of the intervention. Results for residents showed a statistically significant effect, in intent-to-treat analyses, in favour of the STAR-caregivers (STAR-C) intervention, general behavioural disturbance (measured by the Revised Memory and Behaviour Problems Checklist (RMBPC), NPI and ABID) and depression.

Residential care: This setting referred to assisted living residences and nursing homes. The latter included facilities for people with dementia who needed significant nursing care. Three cluster randomised trials were conducted in residential care with a total of 743 residents. ${ }^{165} 179181$

In 15 residential care sites across metropolitan areas in Sydney (Australia), Chenoweth et $a l^{179}$ examined the efficacy of person-centred care versus usual care. The intervention was a high-intensity, person-centred care, based on the needs-driven model in which staff, selected by managers, administered training sessions to caregivers. The topics covered during the sessions were derived from Bradford University's training manual. The duration of the intervention was 4 months, and the overall follow-up was 8 months. The total number of residents enrolled was 289. During follow-up, the mean agitation score (measured with the CMAI) in the person-centred care group decreased significantly, from 47.5 (9.1) at baseline, to $37.2(9.1)$ at 6 months $(p=0.01)$, compared to usual care in which agitation increased from 50.3 (6.8) at baseline to $57.7(6.8)$ at 6 months ( $p$ value not reported).

In 12 residential homes, Fossey $2006^{181}$ allocated 346 residents to an intervention that consisted of training and support delivered to nursing home staff over 10 months, focusing on person-centred care and skill development for the management of agitated behaviour in dementia. The comparison intervention was usual care. The high-intensity intervention was delivered during the whole period of follow-up (12 months) by a psychologist, an occupational therapist or a nurse supervised weekly by the trial investigators. The study's main outcome measure was mean levels of agitated and disruptive behaviour measured with the CMAI, but no significant difference between the groups was detected.

In 10 residential homes, Proctor $1999^{165}$ allocated 120 patients to a staff-based intervention or usual care. The intervention, of high-medium intensity, consisting of training on "psychosocial management of residents" behavioural problems, was delivered through seven, 1-hour seminars by members of the hospital outreach team and psychiatric nurse during the whole period of follow-up (6 months). The seminars covered topics that the staff had identified to improve their knowledge and skills (eg, management of dementia, aggression, etc). The Crichton Royal Behavioural Rating Scale was used to assess behavioural characteristics of residents $(0=$ no problems, $38=$ severe problems). In addition, the geriatric mental state schedule and the diagnostic algorithm AGECAT (Automatic Geriatric Examination for Computer-Assisted Taxonomy) were used to assess the effect of the intervention on residents' organic and depressive symptoms. Despite the control group having mean scores on the Crichton Scale higher than the intervention group at follow-up, this difference was not statistically significant (mean score -0.7 $(-3.0$ to 1.6$))$.

Although the clustered trials reported different types of interventions, intensities, durations and follow-up times, Moniz-Cook et $a l^{176}$ attempted an analysis using two studies and found a significant reduction in behavioural disturbances (SMD, $-0.21,95 \%$ CI -0.39 to $-0.03 ; \mathrm{p}=0.02 ; \mathrm{I}^{2}=9 \%$ ).

Online supplementary etable 12 describes behavioural management technique-based interventions, outcomes and results of the primary studies included in the reviews.

\section{Multicomponent interventions}

Integrated interventions combining psychiatric and nursing home care

Collet $2010^{203}$ (AMSTAR score=5) carried out a SR in MEDLINE, PsycINFO and PubMed to determine the efficacy of interventions that combined psychiatric and nursing home care in nursing home residents. The authors identified 4 RCTs ( $\mathrm{n}=371$ participants), 1 retrospective cohort study and 3 prospective case studies. All the studies used tailored treatment plans that combined psychosocial, nursing, medical and pharmacological interventions. The results of the RCTs were described narratively. Three out of the four randomised trials reported an improvement in behaviour and mood, while 
one trial found no difference among the groups (online supplementary etable 13).

\section{Combination of environmental sensory stimulation}

A SR ${ }^{204}$ that evaluated the effective characteristics of residential LTC settings for people with dementia identified one controlled clinical trial. ${ }^{205}$ The intervention in this trial was provided in five nursing homes and consisted of 15 agitated participants with dementia taking showers, 15 agitated participants with dementia taking walks in an environment where natural elements such as large bright pictures coordinated with audio, including bird songs, bird pictures, the sound of water flowing gently, as well as food (such as banana, pudding and soda). The control group consisted of 15 other agitated participants with dementia that received only usual care. Agitation was measured with a modified version of CMAI. The analysis showed a significant decline in agitation in the treatment group with respect to the comparison group.

\section{Combination of music and hand massage}

Another review $^{72}$ that aimed to assess the role of physical environment in supporting person-centred dining in LTC identified another trial ${ }^{206}$ that was not included in the previous reviews. This trial applied an experimental $3 \times 3$ repeated measures design and included 41 residents with dementia living in three SCUs. Participants were mostly women $(78.0 \%)$, with a mean age of 84.5 years $(\mathrm{SD}=6.0)$. Residents in the treatment group received each of three treatments (hand massage, favourite music and the combination of both) with each treatment lasting $10 \mathrm{~min}$; the control group did not receive any treatment. The CMAI was used to measure agitation. The results showed that each single and combined treatment were effective in significantly decreasing agitation immediately following the intervention and one-hour postintervention.

Online supplementary etable 13 describes multicomponent interventions, outcomes and results of the primary studies included in the reviews.

\section{Other interventions}

Exercise therapy

The systematic search identified two reviews ${ }^{207} 208$ that evaluated the efficacy of only exercise as a therapeutic intervention.

The review by Potter $e t a l^{207}$ received 6 points in the AMSTAR assessment and identified 13 randomised trials that evaluated the effects of physical activity on physical functioning, quality of life and depression in older people with dementia. Only four of these trials investigated depression as an outcome using four different rating scales (Geriatric Depression Scale (GDS15); Montgomery-Asberg Depression Rating Scale (MADRS); a Dutch Evaluation scale for older patients (subscale used) and the CSDD) and two trials measured behavioural disturbances (NPI and Stockton Geriatric Rating Scale).
The review authors stated that the methods of randomisation were clear and adequate in six of the trials with only three of these also providing methods of allocation concealment; eight of the trials reported information regarding losses to follow-up and six trials declared intention-to-treat analysis.

The first study, Burgener 2008, ${ }^{209}$ was a small trial $(n=43)$ carried out in community-dwelling older people with dementia. The intervention was multimodal comprising Tai Chi (sitting and standing; $60 \mathrm{~min}, 3$ times-a-week for 40 weeks) and cognitive-behavioural therapies. Depressive symptoms were measured with the GDS15. The authors reported that at 20 weeks of observation, there were no statistical differences between the groups.

The second study, Rolland $2007,{ }^{210}$ was a larger trial $(\mathrm{n}=134)$ carried out in nursing homes. Participants performed exercises including stretching, walking, strength, flexibility and balance training for $60 \mathrm{~min}, 2$ times/week for 40 weeks. Depression was evaluated using the MADRS. After 12 months of observation, the MADRS score $(13.4 \pm 8.0)$ was higher in the intervention group than in the control group $(14.8 \pm 7.2)$, but without any statistical difference.

The third study ${ }^{103}$ was also a small study $(n=25)$ conducted in a psychiatric hospital. The invention was composed of strength, balance and flexibility exercises with music, 30 min daily for 12 weeks. Depression was measured in older patients with the subscale Beoordelingsschaal voor Oudere Patienten. At 3 months follow-up, no significant difference in depressive behaviour was observed.

The last study ${ }^{164}$ was a larger trial $(n=153)$ that enrolled community-dwelling patients and their caregivers. The exercise intervention, for patients, comprised aerobic, endurance, strength, balance and flexibility training, 30 min twice weekly, reducing to twice monthly, for 23 weeks. Caregivers were given training in behavioural management techniques. The CSDD was used to assess depression. At a 2-year follow-up, the mean difference was 2.14 (95\% CI 0.14 to 4.17 ) and statistically significant in favour of the intervention. The four trials used different types of interventions, outcome measures and follow-up times that hindered the possibility of performing meta-analyses.

The two randomised trials ${ }^{103} 210$ that considered behavioural disturbances used the NPI and Stockton Geriatric Rating Scale, respectively.

The second review by Thuné-Boyle $e t a t^{208}$ received an AMSTAR score of 2 and included six studies comprising two small randomised trials $(n=31)$, two prospective design and two repeated measures studies that examined the effect of exercise on BPSD. In the first trial (Hokkanen 2003), the exercise intervention consisted of 16 sessions of dance and rhythmic movement lasting 30$45 \mathrm{~min}$, once-a-week. This trial was already discussed in the dance section. The second trial ${ }^{211}$ aimed to assess the efficacy of a home-based exercise intervention programme to improve the functional performance of 
patients with $\mathrm{AD}$. The intervention consisted of a daily programme of aerobic, balance and flexibility and strength training, given to patients and caregivers. Depression and apathy were measured using NPI and the CSDD at 6 and 12 weeks. Online supplementary etable 14 describes exercise therapy, outcomes and results of the primary studies included in the reviews.

\section{Animal-assisted therapy}

One review ${ }^{212}$ performed a comprehensive literature search in PubMed, EMBASE and PsycINFO to identify pertinent studies that evaluated the efficacy of animalassisted therapy (AAT) in older patients with dementia or other psychiatric disorders. The authors identified 23 eligible studies of which 18 recruited patients with dementia, but only 10 studies investigated the effect of AAT on BPSD. The design of the studies was as follows: 3 case-control and 7 repeated measures (eg, interrupted time series analysis) studies. Overall, the authors concluded that AAT may have positive influences on patients with dementia by reducing the degree of agitation and improving the amount and quality of social interaction. However, they advocated more research examining the issue of optimal AAI duration, frequency of sessions and suitable target group.

\section{Primary studies}

Churchill $e t a l^{13}$ included 28 residents of three SCUs with dementia (25\% women; mean age 83.8 years; dementia evaluated with Bourke Dementia Rating Scale). The authors administered pet-therapy visits during the difficult 'sundown' time to examine the effect on residents with a history of agitated 'sundowning' behaviour. The active group was exposed to 30-min interaction with an investigator and a dog, which ameliorated agitated/aggressive behaviour measured with the Agitated Behaviours Mapping Instrument Scale. However, the study did not report the $p$ values. In addition, the variability in resident response over time after the departure of the dog was not explored.

The effect of dog-based AAT was also evaluated in another special care unit. McCabe et $a l^{214}$ enrolled 22 participants with dementia (women 68\%; mean age 83.7, range 68-96 years). The study introduced a resident dog and agitated behaviour was measured using the Nursing Home Behaviour Problem Scale. Data were collected 1 week before and for the first 4 weeks after introduction of the dog. The authors reported a significant reduction in daytime behavioural disturbances among residents, but not during evening shift.

In a small pilot study, Richeson ${ }^{215}$ evaluated visiting therapy dogs in 15 residents with dementia (14 women; age range 63-99 years; dementia MMSE mean score: 3.9; $26 \%$ with depression). The session with visiting therapy dogs lasted 1 hour daily for 3 weeks. Agitated behaviour, measured with the CMAI, decreased significantly after 3 weeks and increased significantly after 2 weeks washout subsequent to the end of AAT.
Libin and Cohen-Mansfield ${ }^{216}$ assessed the efficacy of a robotic cat (NeCoRo) and a soft toy cat in reducing agitated behaviour in nine women with moderate dementia in nursing homes. The intervention consisted of two, 10-min interactive sessions on different days. The robotic cat produced a significant increase in pleasure and interest, but did not reduce agitation. Conversely, the soft toy cat significantly reduced agitation.

Motomura et $a l^{217}$ included 8 women (mean age 84.8 years) residing in a nursing home and evaluated the efficacy of AAT, consisting of two dogs visiting for 1 hour, over four consecutive days, to reduce apathy or irritability. The outcomes were measured using the Geriatric Depression Scale, Physical Self-Maintenance Scale and MMSE. The intervention did not show any significant change on any of the outcomes evaluated.

Sellers $e t a l^{218}$ included four residents with dementia to evaluate the efficacy of a visiting dog. Agitation was measured with the Agitated Behaviours Mapping Instrument and Social Behaviour Observation Checklist. The authors reported that the intervention reduced agitated behaviour during treatment and increased observed social behaviour, but data and $\mathrm{p}$ values were not reported.

\section{Dining room environment}

Two small $(\mathrm{n}=38)$ pre-post studies included in Whear's review ${ }^{85}$ examined the effect of improved lighting and table-setting contrast in a dining room environment. One study ${ }^{219}$ (Brush 2002; n=25) found a positive effect on problem behaviours using the Meal Assistance Screening Tool, while the other study ${ }^{220}$ found a statistically significant reduction in daily agitation.

\section{Special care units}

In a Cochrane review, Lai 2009 (AMSTAR=8) examined SCUs for dementia individuals with behavioural problems. SCUs are characterised by trained staff, special care programmes, an altered physical environment and involvement of families. This SR included one quasi-experimental study and seven observational studies (six prospective cohort studies and one prospective casecontrolled study). The absence of randomised trials is likely a consequence of important practical and ethical issues in applying this methodology in older participants with dementia and behavioural problems. Only one casecontrolled study evaluated agitation and used NPI and CMAI to measure the outcome in 65 participants with dementia. ${ }^{221}$ The results showed no significant changes in outcomes at 3 months; however, there were small, but significant improvements in the NPI score in favour of the SCU group at 6 months (WMD $-4.30(95 \% \mathrm{CI}-7.22$ to -1.38 ), 12 months (WMD -4.30 (95\% CI -7.22 to $-1.38)$ ) and 18 months (WMD -5.40 (95\% CI -9.16 to $-1.65)$ ). The same study also evaluated the effect of SCU on mood at 3 months, and the results showed a small significant effect in favour of SCU (WMD -6.30 (95\% CI -7.88 to -4.72$))^{221}$ 


\section{DISCUSSION}

Given the well-known negative side effects of commonly prescribed drugs to control behavioural disturbances (BPSD) in patients with dementia, non-pharmacological interventions have gained increasing attention in recent years as an alternative first-line approach to treat BPSD. This overview addresses the evidence supporting the efficacy of these interventions in community and residential care settings. We identified a number of SRs, which often focused on single interventions although, in several instances, multicomponent interventions were also examined. With the present study, using the primary studies included in the SRs, we have created a compendium of the types of non-pharmacological interventions, including the component of each single intervention, the dosage (when available) and the duration of the treatment.

In the absence of a validated taxonomy, we categorised the interventions according to the following classification: sensory stimulation interventions; cognitive/ emotion-oriented interventions; behaviour management techniques (further subdivided according to the recipient of the intervention, ie, the person with dementia, the caregiver or the staff); multicomponent interventions and other interventions, such as exercise and animal-assisted therapies.

Among sensory simulation interventions, the only convincingly effective intervention for reducing behavioural symptoms (specifically agitation and aggressive behaviour) was music therapy. According to the most comprehensive review of music therapy, this treatment also reduced anxiety. However, the evidence supporting the effectiveness of music therapy was limited by moderate, but significant, heterogeneity, probably related to the variability of the intervention (eg, type of music, active involvement, such as singing/playing a musical instrument and dancing, or passive involvement, such as listening) and the heterogeneity of the patient population in terms of the severity of dementia and the type of dementia. The efficacy of aromatherapy and massage therapy, both associated with conflicting results, remains unknown. Light therapy and SMST therapy did not show any noteworthy effect for clinical practice.

The body of evidence concerning cognitive/emotionoriented interventions, which include reminiscence therapy, SPT and validation therapy, had important methodological limitations. The quality of the primary studies was low, as reported by the review authors, and the sample size of the studies was not powered to detect statistically significant effects. Even when it was possible to combine studies in a meta-analysis, for example, for SPT, the pooled estimated effect was not statistically significant. Added to these shortcomings was the variability in the length and type of the interventions and the multitude of outcomes measured. Overall, convincing evidence supporting the effectiveness of these psychological interventions was lacking.
The most frequently assessed intervention in several trials was behavioural management techniques. The elements in this type of intervention included behavioural or cognitive-behavioural therapy, functional analysis of specific behaviour, individualised behavioural reinforcement strategies, communication training and other therapies, such as habit training, progressive muscle relaxation and token economies. ${ }^{31}$ The body of evidence supporting the effectiveness of behavioural management techniques includes positive and negative studies. Among the types of behavioural management techniques which aimed to enhance communication skills, formal caregiver training and dementia mapping provided in residential care were found to be effective at reducing agitation. The evidence was convincing when the intervention was supervised by healthcare professionals, with the effectiveness possibly persisting for 3-6 months.

There is some evidence that multicomponent interventions that use a comprehensive, integrated multidisciplinary approach combining medical, psychiatric and nursing interventions can reduce severe behavioural problems in nursing home patients.

Other interventions such as animal-assisted and exercise therapy did not show any convincing effect on any BPSD.

\section{Strengths of this overview}

The present overview represents a substantial update of a previous overview, ${ }^{31}$ using a search strategy launched in 2009, that provided a comprehensive synthesis of the evidence about non-pharmacological interventions on BPSD. We systematically searched reviews available in four electronic databases and systematically collected the evidence regarding non-pharmacological interventions for the treatment of behavioural disturbances in patients with dementia. To allow the identification of SRs of all potential non-pharmacological interventions, we used a highly sensitive search strategy by avoiding the inclusion of any specific name of non-pharmacological interventions. We also assessed the methodological quality of the reviews using the AMSTAR criteria. Another strength of the present overview was the adoption of a systematic and transparent method, and the use of duplicate, independent reviewers who performed the phases of study selection, data abstraction and data interpretation separately. ${ }^{38}$

\section{Limitations of the interpretation of the results}

Overall, the SRs had a number of methodological limitations that could have affected the confidence in the reported results. First, the heterogeneity of the types and characteristics of the interventions, even within the same class of non-pharmacological interventions, was the most significant problem that emerged from the present study. One implication is that there are serious methodological issues that question the correctness, in our opinion, of combining studies in a meta-analysis, as 
some authors have previously performed. Moreover, in some studies, the description of the interventions is too vague to allow a complete understanding of what was actually performed. In addition, even in cases in which the intervention is well characterised, the dosage of the intervention, and the means used for its delivery, varied considerably. For example, in the case of music therapy, music interventions such as listening to music via headphones, based on participants' musical preferences, ${ }^{87}$ differed from listening, playing percussion instruments, singing, movement or dance ${ }^{86}$ and was observed across all nine trials combined in the meta-analysis. In the case of aromatherapy, there were several essential oils that were used in the primary studies, but in some instances, even when similar components were used (eg, Melissa essential oil), the mode of administration differed among trials. Similarly, there was great variation in the intensity (from 2500 to 10000 lux), duration (19 hours), frequency of exposure (10 days to 10 weeks) and type of device used (Dawn-Dusk Simulator ${ }^{222}$ ), when light therapy was investigated for behavioural problems in dementia.

The variation in the characteristics of the interventions was particularly pronounced in the trials ascribed to behavioural management techniques. The trials used different conceptual frameworks, and sometimes broad and quite generic descriptions, to describe the interventions that at times were difficult to interpret and which influenced the content and quality of evidence of the SRs. In this area, it is therefore difficult to produce a satisfactory classification, which implies that different SRs did not consider the same group of studies, even when they clearly investigated non-pharmacological interventions specifically designed to improve behavioural management.

Finally, the arbitrary age cut-off of the patients (more than 60 years of age) and the exclusion of reviews published before 2009 constitute other limitations of the present overview. We did not evaluate the methodological quality of the primary studies included in the reviews, as this will be the scope of our next publication, in which we will apply the GRADE criteria. ${ }^{38}$

\section{CONCLUSION}

This overview succeeded in providing a complete and up-to-date compendium of non-pharmacological interventions in older people with dementia, using recently published SRs and meta-analyses. The most promising treatments appeared to be music therapy and some behavioural management techniques, particularly those involving caregiver-oriented and staff-oriented interventions. Despite the considerable number of published articles included in this overview, the evidence supporting the efficacy of non-pharmacological interventions is limited due to methodological quality and sample size and to the presence of important variations in the taxonomy of the non-pharmacological interventions, the outcomes assessed and the tools used to evaluate the outcomes.

\section{Author affiliations}

${ }^{1}$ Geriatrics and Geriatric Emergency Care, Italian National Research Center on Aging (IRCCS-INRCA), Ancona, Italy

${ }^{2}$ Servicio de Geriatría, Hospital Universitario Ramón y Cajal, Madrid, Spain

${ }^{3}$ Department of Internal Medicine (Geriatrics), Ghent University, Ghent, Belgium

${ }^{4}$ Landspitali University Hospital Reykjavik, Reykjavik, Iceland

${ }^{5}$ Department of Medicine for the Elderly, Woodend Hospital, Aberdeen, UK

${ }^{6}$ Department of Medicine, University College Cork, Cork, Ireland

7‘Golgi Cenci' Foundation, Milan, Italy

\section{Twitter Follow Roy Soiza @AbdnGeriatrics}

Contributors IA, JMR, AC, RS, AC-J and DO conceived and designed the study. The manuscript of this protocol was drafted by IA, JMR, AC, RS, AC-J, AdG and BHM and revised by MP, AnG, FMT and GDA. IA and JMR designed the search strategies; IA, JMR, FMT and GDA performed the search, screening and assessment independently. AC arbitrated disagreements during the review. All authors contributed to data analysis and critical revision of the paper; additionally every author approved the final version.

Funding The research leading to these results has received funding from the European Union Seventh Framework programme (FP7/2007-2013) under grant agreement no. 305930 (SENATOR).

Disclaimer The funders had no role in the study design, data collection and analysis, the decision to publish or the preparation of the manuscript.

Competing interests None declared.

Provenance and peer review Not commissioned; externally peer reviewed.

Data sharing statement No additional data are available.

Open Access This is an Open Access article distributed in accordance with the Creative Commons Attribution Non Commercial (CC BY-NC 4.0) license, which permits others to distribute, remix, adapt, build upon this work noncommercially, and license their derivative works on different terms, provided the original work is properly cited and the use is non-commercial. See: http:// creativecommons.org/licenses/by-nc/4.0/

\section{REFERENCES}

1. Prince $\mathrm{M}$, Bryce $\mathrm{R}$, Albanese $\mathrm{E}$, et al. The global prevalence of dementia: a systematic review and metaanalysis. Alzheimers Dement 2013;9:63-75. e2.

2. Grasset L, Brayne C, Joly P, et al. Trends in dementia incidence: evolution over a 10-year period in France. Alzheimers Dement 2016;12:272-80.

3. Rattinger GB, Fauth EB, Behrens S, et al. Closer caregiver and care-recipient relationships predict lower informal costs of dementia care: the Cache County Dementia Progression Study. Alzheimers Dement 2016;12:917-24.

4. Wimo A, Jönsson L, Bond J, et al. The worldwide economic impact of dementia 2010. Alzheimers Dement 2013;9: 1-11.e3.

5. Finkel SI, Costa e Silva J, Cohen G, et al. Behavioral and psychological signs and symptoms of dementia: a consensus statement on current knowledge and implications for research and treatment. Int Psychogeriatr 1996;8(Suppl 3):497-500.

6. Lyketsos CG, Carrillo MC, Ryan JM, et al. Neuropsychiatric symptoms in Alzheimer's disease. Alzheimers Dement 2011;7:532-9.

7. Geda YE, Schneider LS, Gitlin LN, et al. Neuropsychiatric symptoms in Alzheimer's disease: past progress and anticipation of the future. Alzheimers Dement 2013;9:602-8.

8. Ismail Z, Smith EE, Geda Y, et al. Neuropsychiatric symptoms as early manifestations of emergent dementia: provisional diagnostic criteria for mild behavioral impairment. Alzheimers Dement 2016;12:195-202.

9. Kales HC, Gitlin LN, Lyketsos CG. Assessment and management of behavioral and psychological symptoms of dementia. BMJ 2015;350:h369. 
10. Petrovic M, Hurt C, Collins D, et al. Clustering of behavioural and psychological symptoms in dementia (BPSD): a European Alzheimer's disease consortium (EADC) study. Acta Clin Belg 2007:62:426-32.

11. Pawłucka U, Brzyski P, Kubicz D, et al. The determinants of behavioral symptoms in long-term care facility residents. Eur Geriatr Med 2016;7:157-62.

12. Savva GM, Zaccai J, Matthews FE, et al. Prevalence, correlates and course of behavioural and psychological symptoms of dementia in the population. Br J Psychiatry 2009;194:212-19.

13. Hendriks SA, Smalbrugge M, Galindo-Garre F, et al. From admission to death: prevalence and course of pain, agitation, and shortness of breath, and treatment of these symptoms in nursing home residents with dementia. J Am Med Dir Assoc 2015;16:475-81.

14. Ryu SH, Katona C, Rive B, et al. Persistence of and changes in neuropsychiatric symptoms in Alzheimer disease over 6 months: the LASER-AD study. Am J Geriatr Psychiatry 2005;13:976-83.

15. Givens JL, Jones RN, Mazor KM, et al. Development and psychometric properties of the family distress in advanced dementia scale. J Am Med Dir Assoc 2015;16:775-80.

16. Wetzels RB, Zuidema SU, de Jonghe JF, et al. Determinants of quality of life in nursing home residents with dementia. Dement Geriatr Cogn Disord 2010;29:189-97.

17. Gaugler JE, Yu F, Krichbaum K, et al. Predictors of nursing home admission for persons with dementia. Med Care 2009;47: 191-8.

18. Cabrera E, Sutcliffe $\mathrm{C}$, Verbeek $\mathrm{H}$, et al. Non-pharmacological interventions as a best practice strategy in people with dementia living in nursing homes. A systematic review. Eur Geriatr Med 2015;6:134-50.

19. Cammisuli DM, Danti S, Bosinelli F, et al. Non-pharmacological interventions for people with Alzheimer's disease: a critical review of the scientific literature from the last ten years. Eur Geriatr Med 2016;7:57-64.

20. Howard R, McShane R, Lindesay J, et al. Donepezil and memantine for moderate-to-severe Alzheimer's disease. $N$ Engl $J$ Med 2012;366:893-903.

21. Olin J, Schneider L. Galantamine for Alzheimer's disease. Cochrane Database Syst Rev 2002(3):CD001747.

22. Locca JF, Büla CJ, Zumbach S, et al. Pharmacological treatment of behavioral and psychological symptoms of dementia (BPSD) in nursing homes: development of practice recommendations in a Swiss canton. J Am Med Dir Assoc 2008;9:439-48.

23. Porsteinsson AP, Drye LT, Pollock BG, et al. Effect of citalopram on agitation in Alzheimer disease: the CitAD randomized clinical trial. JAMA 2014;311:682-91.

24. Bierman EJ, Comijs HC, Gundy CM, et al. The effect of chronic benzodiazepine use on cognitive functioning in older persons: good, bad or indifferent? Int J Geriatr Psychiatry 2007;22:1194-200.

25. Maher AR, Maglione M, Bagley S, et al. Efficacy and comparative effectiveness of atypical antipsychotic medications for off-label uses in adults: a systematic review and meta-analysis. JAMA 2011;306:1359-69.

26. Berry SD, Placide SG, Mostofsky E, et al. Antipsychotic and benzodiazepine drug changes affect acute falls risk differently in the nursing home. J Gerontol A Biol Sci Med Sci 2016;71:273-8.

27. Howard RJ, Juszczak E, Ballard CG, et al. Donepezil for the treatment of agitation in Alzheimer's disease. $N$ Engl $\mathrm{J} \mathrm{Med}$ 2007;357:1382-92.

28. Matsunaga S, Kishi T, Iwata N. Memantine monotherapy for Alzheimer's disease: a systematic review and meta-analysis. PLoS ONE 2015;10:e0123289.

29. Seitz DP, Brisbin S, Herrmann N, et al. Efficacy and feasibility of nonpharmacological interventions for neuropsychiatric symptoms of dementia in long term care: a systematic review. J Am Med Dir Assoc 2012;13:503-06. e2.

30. Zetteler J. Effectiveness of simulated presence therapy for individuals with dementia: a systematic review and meta-analysis. Aging Ment Health 2008;12:779-85.

31. O'Neil ME, Freeman M, Portland V. A systematic evidence review of non-pharmacological interventions for behavioral symptoms of dementia. Washington (DC): Department of Veterans Affairs, 2011.

32. Abraha I, Trotta F, Rimland JM, et al. Efficacy of non-pharmacological interventions to prevent and treat Delirium in older patients: a systematic overview. The SENATOR project ONTOP Series. PLOS ONE 2015;10:e0123090.

33. Vélez-Díaz-Pallarés M, Lozano-Montoya I, Correa-Pérez A, et al. Non-pharmacological interventions to prevent or treat pressure ulcers in older patients: Clinical practice recommendations. The SENATOR-ONTOP series. Eur Geriatr Med 2016;7:142-8.
34. Lozano-Montoya I, Velez-Diaz-Pallares M, Abraha I, et al. Nonpharmacologic interventions to prevent pressure ulcers in older patients: an overview of systematic reviews (the software ENgine for the assessment and optimization of drug and non-drug therapy in older peRsons [SENATOR] definition of optimal evidence-based non-drug therapies in older people [ONTOP] series). J Am Med Dir Assoc 2016;17:370 e1-70 e10.

35. Velez-Diaz-Pallares M, Lozano-Montoya I, Abraha I, et al. Nonpharmacologic interventions to heal pressure ulcers in older patients: an overview of systematic reviews (the SENATORONTOP series). J Am Med Dir Assoc 2015;16:448-69.

36. Rimland JM, Dell'Aquila G, O'Mahony D, et al. Meta-analysis of multifactorial interventions to prevent falls of older adults in care facilities. J Am Geriatr Soc 2015;63:1972-3.

37. Rimland JM, Abraha I, Dell'Aquila G, et al. Effectiveness of non-pharmacological interventions to prevent falls in older people: a systematic overview. The SENATOR Project ONTOP Series. PLOS ONE 2016;11:e0161579.

38. Abraha I, Cruz-Jentoft A, Soiza RL, et al. Evidence of and recommendations for non-pharmacological interventions for common geriatric conditions: the SENATOR-ONTOP systematic review protocol. BMJ Open 2015;5:e007488.

39. Shea BJ, Grimshaw JM, Wells GA, et al. Development of AMSTAR: a measurement tool to assess the methodological quality of systematic reviews. BMC Med Res Methodol 2007;7:10.

40. Savovic J, Jones HE, Altman DG, et al. Influence of reported study design characteristics on intervention effect estimates from randomized, controlled trials. Ann Intern Med 2012;157:429-38.

41. Abraha I, Cherubini A, Cozzolino F, et al. Deviation from intention to treat analysis in randomised trials and treatment effect estimates: meta-epidemiological study. BMJ 2015;350:h2445.

42. Chan AW, Hróbjartsson A, Haahr MT, et al. Empirical evidence for selective reporting of outcomes in randomized trials: comparison of protocols to published articles. JAMA 2004;291:2457-65.

43. Guyatt GH, Oxman AD, Vist G, et al. GRADE guidelines: 4. Rating the quality of evidence--study limitations (risk of bias). J Clin Epidemiol 2011;64:407-15.

44. Robinson N, Lorenc A, Liao X. The evidence for Shiatsu: a systematic review of Shiatsu and acupressure. BMC Complement Altern Med 2011;11:88.

45. Lin LC, Yang MH, Kao CC, et al. Using acupressure and Montessori-based activities to decrease agitation for residents with dementia: a cross-over trial. J Am Geriatr Soc 2009;57:1022-9.

46. Nguyen QA, Paton C. The use of aromatherapy to treat behavioural problems in dementia. Int J Geriatr Psychiatry 2008;23:337-46.

47. Fung JKKM, Tsang HWH, Chung RCK. A systematic review of the use of aromatherapy in treatment of behavioral problems in dementia. Geriatr Gerontol Int 2012;12:372-82.

48. Forrester LT, Maayan N, Orrell M, et al. Aromatherapy for dementia Cochrane Database Syst Rev 2014;(2):CD003150.

49. Fu CY, Moyle W, Cooke M. A randomised controlled trial of the use of aromatherapy and hand massage to reduce disruptive behaviour in people with dementia. BMC Complement Altern Med 2013;13:165

50. Lin PW, Chan WC, Ng BF, et al. Efficacy of aromatherapy (Lavandula angustifolia) as an intervention for agitated behaviours in Chinese older persons with dementia: a cross-over randomized trial. Int J Geriatr Psychiatry 2007;22:405-10.

51. O'Connor DW, Eppingstall B, Taffe J, et al. A randomized, controlled cross-over trial of dermally-applied lavender (Lavandula angustifolia) oil as a treatment of agitated behaviour in dementia. BMC Complement Altern Med 2013;13:315.

52. Smallwood J, Brown R, Coulter F, et al. Aromatherapy and behaviour disturbances in dementia: a randomized controlled trial. Int J Geriatr Psychiatry 2001;16:1010-13.

53. Ballard CG, O'Brien JT, Reichelt K, et al. Aromatherapy as a safe and effective treatment for the management of agitation in severe dementia: the results of a double-blind, placebo-controlled trial with Melissa. J Clin Psychiatry 2002;63:553-8.

54. Burns A, Perry E, Holmes C, et al. A double-blind placebo-controlled randomized trial of Melissa officinalis oil and donepezil for the treatment of agitation in Alzheimer's disease. Dement Geriatr Cogn Disord 2011;31:158-64.

55. Akhondzadeh S, Noroozian M, Mohammadi M, et al. Melissa officinalis extract in the treatment of patients with mild to moderate Alzheimer's disease: a double blind, randomised, placebo controlled trial. J Neurol Neurosurg Psychiatr 2003;74:863-6.

56. Burleigh S, Armstrong C. On the scent of a useful therapy. J Dement Care 1997;5:21-3.

57. Gray SG, Clair AA. Influence of aromatherapy on medication administration to residential-care residents with dementia and 
behavioral challenges. Am J Alzheimers Dis Other Demen 2002:17:169-74

58. Holmes C, Hopkins V, Hensford C, et al. Lavender oil as a treatment for agitated behaviour in severe dementia: a placebo controlled study. Int J Geriatr Psychiatry 2002;17:305-8.

59. Jimbo D, Kimura $\mathrm{Y}$, Taniguchi M, et al. Effect of aromatherapy on patients with Alzheimer's disease. Psychogeriatrics 2009;9:173-9.

60. Kilstoff K, Chenoweth L. New approaches to health and well-being for dementia day-care clients, family carers and day-care staff. Int J Nurs Pract 1998;4:70-83.

61. Cameron $\mathrm{H}$, du Toit S, Richard G, et al. Using lemon balm oil to reduce aggression and agitation in dementia: results of a pilo study. J Dement Care 2011;19:36-8.

62. Cohen-Mansfield J. Nonpharmacologic interventions for inappropriate behaviors in dementia: a review, summary, and critique. Am J Geriatr Psychiatry 2001;9:361-81.

63. Viggo Hansen N, Jørgensen T, Ørtenblad L. Massage and touch for dementia. Cochrane Database Syst Rev 2006;(4):CD004989.

64. Remington R. Calming music and hand massage with agitated elderly. Nurs Res 2002;51:317-23.

65. Moyle W, Murfield JE, O'Dwyer S, et al. The effect of massage on agitated behaviours in older people with dementia: a literature review. J Clin Nurs 2013;22:601-10.

66. Holliday-Welsh DM, Gessert CE, Renier CM. Massage in the management of agitation in nursing home residents with cognitive impairment. Geriatr Nurs 2009;30:108-17.

67. Forbes D, Blake Catherine M, Thiessen Emily J, et al. Light therapy for improving cognition, activities of daily living, sleep, challenging behaviour, and psychiatric disturbances in dementia. Cochrane Database Syst Rev 2014;(2):CD003946.

68. Ancoli-Israel S, Martin JL, Gehrman P, et al. Effect of light on agitation in institutionalized patients with severe Alzheimer disease. Am J Geriatr Psychiatry 2003:11:194-203.

69. Burns A, Allen $\mathrm{H}$, Tomenson B, et al. Bright light therapy for agitation in dementia: a randomized controlled trial. Int Psychogeriatr 2009;21:711-21.

70. Dowling GA, Mastick J, Hubbard EM, et al. Effect of timed bright light treatment for rest-activity disruption in institutionalized patients with Alzheimer's disease. Int J Geriatr Psychiatry 2005;20: 738-43.

71. Riemersma-van der Lek RF, Swaab DF, Twisk J, et al. Effect of bright light and melatonin on cognitive and noncognitive function in elderly residents of group care facilities: a randomized controlled trial. JAMA 2008;299:2642-55.

72. Chaudhury $\mathrm{H}$, Hung $\mathrm{L}$, Badger $\mathrm{M}$. The role of physical environment in supporting person-centered dining in long-term care: a review of the literature. Am J Alzheimers Dis Other Demen 2013;28: 491-500.

73. Barrick AL, Sloane PD, Williams CS, et al. Impact of ambient bright light on agitation in dementia. Int J Geriatr Psychiatry 2010;25: 1013-21.

74. Padilla R. Effectiveness of environment-based interventions for people with Alzheimer's disease and related dementias. Am J Occup Ther 2011;65:514-22.

75. Hickman SE, Barrick AL, Williams CS, et al. The effect of ambient bright light therapy on depressive symptoms in persons with Dementia. J Am Geriatr Soc 2007:55:1817-24.

76. Whear R, Coon JT, Bethel A, et al. What is the impact of using outdoor spaces such as gardens on the physical and mental well-being of those with dementia? A systematic review of quantitative and qualitative evidence. J Am Med Dir Assoc 2014;15:697-705.

77. Luk KY, Lai KYC, Li CC, et al. The effect of horticultural activities on agitation in nursing home residents with dementia. Int $J$ Geriatr Psychiatry 2011;26:435-6.

78. Gonzalez MT, Kirkevold M. Benefits of sensory garden and horticultural activities in dementia care: a modified scoping review. $J$ Clin Nurs 2014;23:2698-715.

79. Connell BR, Sanford JA, Lewis D. Therapeutic effects of an outdoor activity program on nursing home residents with dementia. J Hous Elderly 2007;21:194-209.

80. Chatterton WB, Baker F Morgan $\mathrm{K}$. The singer or the singing: who sings individually to persons with dementia and what are the effects? Am J Alzheimers Dis Other Demen 2010;25:641-9.

81. McDermott OC, Crellin N, Ridder HM, et al. Music therapy in dementia: a narrative synthesis systematic review. Int J Geriatr Psychiatry 2013;28:781-94

82. Ueda TS, Suzukamo Y, Sato, M, et al. Effects of music therapy on behavioral and psychological symptoms of dementia: a systematic review and meta-analysis. Ageing Res Rev 2013;12:628-41.
83. Vasionyte IM, Madison G. Musical intervention for patients with dementia: a meta-analysis. J Clin Nurs 2013;22:1203-16.

84. Wall M, Duffy A. The effects of music therapy for older people with dementia. Br J Nurs 2010;19:108-13.

85. Whear R, Abbott R, Thompson-Coon J, et al. Effectiveness of mealtime interventions on behavior symptoms of people with dementia living in care homes: a systematic review. J Am Med Dir Assoc 2014;15:185-93.

86. Groene RW. Effectiveness of music therapy 1:1 intervention with individuals having senile dementia of the Alzheimer's type. J Music Ther 1993;30:138-57.

87. Guétin S, Portet F, Picot MC, et al. Effect of music therapy on anxiety and depression in patients with Alzheimer's type dementia: randomised, controlled study. Dement Geriatr Cogn Disord 2009;28:36-46.

88. Ledger AJ, Baker FA. An investigation of long-term effects of group music therapy on agitation levels of people with Alzheimer's disease. Aging Ment Health 2007;11:330-8.

89. Miura $\mathrm{H}$, Kanayama $\mathrm{Y}$, Mogi $\mathrm{N}$, et al. Effect and significance of music therapy on elderly persons with mild dementia. 2005;5:48-57.

90. Sung HC, Chang AM, Abbey J. The effects of preferred music on agitation of older people with dementia in Taiwan. Int $J$ Geriatr Psychiatry 2006:21:999-1000.

91. Sung HC, Chang AM, Lee W-L. A preferred music listening intervention to reduce anxiety in older adults with dementia in nursing homes. J Clin Nurs 2010;19:1056-64.

92. Suzuki M, Kanamori M, Nagasawa S, et al. Music therapy-induced changes in behavioral evaluations, and saliva chromogranin a and immunoglobulin a concentrations in elderly patients with senile dementia. Geriatr Gerontol Int 2007;7:61-71.

93. Tuet RWK, Lam LCW. A preliminary study of the effects of music therapy on agitation in Chinese patients with dementia. Hong Kong J Psychiatry 2006;16:87-91.

94. Ikeda M, Suzuki M, Sawai D, et al. Effects of nursing intervention using rhythmic exercise for patients with severe senile dementia. Nurs Res 2006;39:301-13.

95. Mihara B, Hosoya M, Mihara $\mathrm{Y}$, et al. The effect of music therapy for elderly with dementia: a comparative study between large group and small group sessions. Japanese J Music Ther 2004;4:208-16.

96. Raglio A, Bellelli G, Traficante D, et al. Efficacy of music therapy in the treatment of behavioral and psychiatric symptoms of dementia. Alzheimer Dis Assoc Disord 2008;22:158-62.

97. Sung HC, Chang SM, Lee WL, et al. The effects of group music with movement intervention on agitated behaviours of institutionalized elders with dementia in Taiwan. Complement Ther Med 2006;14:113-19.

98. Choi AN, Lee MS, Cheong KJ, et al. Effects of group music intervention on behavioral and psychological symptoms in patients with dementia: a pilot-controlled trial. Int J Neurosci 2009:119:471-81.

99. Goka $F$. The effects of combined music and reminiscence therapy for small groups of the elderly with senile dementia of Alzheimer type, and the efficacy of the evaluation method. Japanese J Music Ther 2005;5:25-38.

100. Raglio A, Bellelli G, Traficante D, et al. Efficacy of music therapy treatment based on cycles of sessions: a randomised controlled trial. Aging Ment Health 2010;14:900-4.

101. Smith GH. A comparison of the effects of three treatment interventions on cognitive functioning of Alzheimer patients. Music Ther 1986;6:41-56.

102. Suzuki M, Kanamori M, Watanabe $M$, et al. Behavioral and endocrinological evaluation of music therapy for elderly patients with dementia. Nurs Health Sci 2004;6:11-18.

103. Van de Winckel A, Feys H, De Weerdt W, et al. Cognitive and behavioural effects of music-based exercises in patients with dementia. Clin Rehabil 2004:18:253-60.

104. Svansdottir HB, Snaedal J. Music therapy in moderate and severe dementia of Alzheimer's type: a case-control study. Int Psychogeriatr 2006:18:613-21.

105. Clark ME, Lipe AW, Bilbrey M. Use of music to decrease aggressive behaviors in people with dementia. $J$ Gerontol Nurs 1998;24:10-17.

106. Cooke M, Moyle W, Shum D, et al. A randomized controlled trial exploring the effect of music on quality of life and depression in older people with Dementia. J Health Psychology 2010;15:765-76.

107. Nair B, Heim C, Krishnan C, et al. The effect of Baroque music on behavioural disturbances in patients with dementia. Australas J Ageing 2011;30:11-15.

108. Raglio A, Oasi O, Gianotti M, et al. Effects of music therapy on psychological symptoms and heart rate variability in patients with dementia. A pilot study. Current Aging Sci 2010:242-6. 
109. Irish M, Cunningham CJ, Walsh JB, et al. Investigating the enhancing effect of music on autobiographical memory in mild Alzheimer's disease. Dement Geriatr Cogn Disord 2006;22:108-20.

110. Denney A. Quiet music. An intervention for mealtime agitation? J Gerontol Nurs 1997;23:16-23.

111. Hicks-Moore SL. Relaxing music at mealtime in nursing homes: effects on agitated patients with dementia. $J$ Gerontol Nurs 2005;31:26-32.

112. Ragneskog $\mathrm{H}$, Kihlgren M, Karlsson I, et al. Dinner music for demented patients: analysis of video-recorded observations. Clin Nurs Res 1996;5:262-77. Discussion 78-82.

113. Thomas DW, Smith M. The effect of music on caloric consumption among nursing home residents with Dementia of the Alzheimer's type. Act Adapt Aging 2009;33:1-16.

114. Kiepe MS, Barbara S, Thomas K. Effects of dance therapy and ballroom dances on physical and mental illnesses: a systematic review. Arts Psychotherapy 2012;39:404-11.

115. Guzman-Garcia A, Hughes JC, James IA, et al. Dancing as a psychosocial intervention in care homes: a systematic review of the literature. Int J Geriatr Psychiatry 2013;28:914-24.

116. Hokkanen L, Rantala L, Remes AM, et al. Dance and movement therapeutic methods in management of dementia: a randomized, controlled study. J Am Geriatr Soc 2008;56:771-2.

117. Chung JC, Lai CK, Chung PM, et al. Snoezelen for dementia. Cochrane Database Syst Rev 2002;(4):CD003152.

118. Baker R, Bell S, Baker $\mathrm{E}$, et al. A randomized controlled trial of the effects of multi-sensory stimulation (MSS) for people with dementia. Br J Clin Psychology 2001;40:81-96.

119. Baker R. \& Dowling Z. (1995) INTERACT. A New Measure of Response to Multi-Sensory Environments. Research Publication. Research and Development Support Unit, Poole Hospital, Dorset.

120. Baker R, Holloway J, Holtkamp CCM, et al. Effects of multi-sensory stimulation for people with dementia. J Adv Nurs 2003;43:465-77.

121. van Weert JC, van Dulmen AM, Spreeuwenberg PM, et al. Effects of snoezelen, integrated in $24 \mathrm{~h}$ dementia care, on nurse-patient communication during morning care. Patient Educ Couns 2005;58:312-26.

122. van Weert JC, van Dulmen AM, Spreeuwenberg PM, et al. Behavioral and mood effects of Snoezelen integrated into 24-hour dementia care. J Am Geriatr Soc 2005;53:24-33.

123. $\mathrm{Bi} X, \mathrm{Lv} \mathrm{H}, \mathrm{Chen} \mathrm{BL}$, et al. Effects of transcutaneous electrical nerve stimulation on pain in patients with spinal cord injury: a randomized controlled trial. J Phys Ther Sci 2015;27:23-5.

124. Salami O, Lyketsos C, Rao V. Treatment of sleep disturbance in Alzheimer's dementia. Int J Geriatr Psychiatry 2011;26:771-82.

125. Cameron $\mathrm{M}$, Lonergan $\mathrm{E}$, Lee $\mathrm{H}$. Transcutaneous electrical nerve stimulation (TENS) for dementia. Cochrane Database Syst Rev 2003(3):CD004032.

126. Scherder E, Knol D, van Someren E, et al. Effects of low-frequency cranial electrostimulation on the rest-activity rhythm and salivary cortisol in Alzheimer's disease. Neurorehabil Neural Repair 2003;17:101-8.

127. Scherder EJ, Bouma A, Steen L. Influence of transcutaneous electrical nerve stimulation on memory in patients with dementia of the Alzheimer type. J Clin Exp Neuropsychol 1992;14: 951-60.

128. Scherder EJ, Deijen JB, Vreeswijk SH, et al. Crania electrostimulation (CES) in patients with probable Alzheimer's disease. Behav Brain Res 2002;128:215-17.

129. Scherder EJ, Van Someren EJ, Bouma A, et al Effects of transcutaneous electrical nerve stimulation (TENS) on cognition and behaviour in aging. Behav Brain Res 2000;111:223-5.

130. Scherder EJ, Van Someren EJ, Swaab DF. Transcutaneous electrical nerve stimulation (TENS) improves the rest-activity rhythm in midstage Alzheimer's disease. Behav Brain Res 1999:101:105-7.

131. Van Someren EJ, Scherder EJ, Swaab DF. Transcutaneous electrical nerve stimulation (TENS) improves circadian rhythm disturbances in Alzheimer disease. Alzheimer Dis Assoc Disord 1998;12:114-18.

132. Hozumi S, Hori H, Okawa M, et al. Favorable effect of transcranial electrostimulation on behavior disorders in elderly patients with dementia: a double-blind study. Int J Neurosci 1996;88:1-10.

133. Woods B, Aguirre E, Spector AE, et al. Cognitive stimulation to improve cognitive functioning in people with dementia. Cochrane Database Syst Rev 2012;(2):CD005562.

134. Aguirre E, Woods RT, Spector A, et al. Cognitive stimulation for dementia: a systematic review of the evidence of effectiveness from randomised controlled trials. Ageing Res Rev 2013;12:253-62.
135. Alves J, Magalhaes R, Thomas RE, et al. Is there evidence for cognitive intervention in Alzheimer disease? A systematic review of efficacy, feasibility, and cost-effectiveness. Alzheimer Dis Assoc Disord 2013;27:195-203.

136. Carrion C, Aymerich M, Baillés E, et al. Cognitive psychosocial intervention in dementia: a systematic review. Dement Geriatr Cogn Disord 2013;36:363-75

137. Yu F, Rose KM, Burgener SC, et al. Cognitive training for earlystage Alzheimer's disease and dementia. J Gerontol Nurs 2009;35:23-9.

138. Olazarán J, Reisberg B, Clare L, et al. Nonpharmacological therapies in Alzheimer's disease: a systematic review of efficacy. Dement Geriatr Cogn Disord 2010;30:161-78.

139. Zientz J, Rackley A, Chapman SB, et al. Evidence-based practice recommendations for dementia: educating caregivers on Alzheimer's disease and training communication strategies. J Med Speech Lang Pathol 2007; 15:liii-Ixiv.

140. Baines S, Saxby P, Ehlert K. Reality orientation and reminiscence therapy. A controlled cross-over study of elderly confused people. Br J Psychiatry 1987;151:222-31.

141. Ferrario E, Cappa G, Molaschi M, et al. Reality orientation therapy in institutionalized elderly patients: preliminary results. Arch Gerontol Geriatr 1991:12:139-42.

142. Onder G, Zanetti O, Giacobini E, et al. Reality orientation therapy combined with cholinesterase inhibitors in Alzheimer's disease: randomised controlled trial. Br J Psychiatry 2005;187:450-5.

143. Robichaud L, Hebert R, Desrosiers J. Efficacy of a sensory integration program on behaviors of inpatients with dementia. Am J Occup Ther 1994:48:355-60.

144. Kim SY, Yoo EY, Jung MY, et al. A systematic review of the effects of occupational therapy for persons with dementia: a meta-analysis of randomized controlled trials. NeuroRehabilitation 2012;31: 107-15.

145. Kurz AF, Leucht S, Lautenschlager NT. The clinical significance of cognition-focused interventions for cognitively impaired older adults: a systematic review of randomized controlled trials. Int Psychogeriatr 2011;23:1364-75.

146. Blake M. Group reminiscence therapy for adults with dementia: a review. Br J Community Nurs 2013;18:228-33.

147. Subramaniam $P$, Woods $B$. The impact of individual reminiscence therapy for people with dementia: systematic review. Expert Rev Neurother 2012;12:545-55.

148. Deponte A, Missan R. Effectiveness of validation therapy (VT) in group: preliminary results. Arch Gerontol Geriatr 2007;44:113-17.

149. Wang JJ, Yen M, OuYang WC. Group reminiscence intervention in Taiwanese elders with dementia. Arch Gerontol Geriatr 2009;49:227-32.

150. Haight BK, Gibson F, Michel Y. The Northern Ireland life review/life storybook project for people with dementia. Alzheimers Dement 2006;2:56-8

151. Morgan S, Woods R. Life review with people with dementia in care homes: a preliminary randomized controlled trial. 2010;1:43-60.

152. Lai CK, Chi I, Kayser-Jones J. A randomized controlled trial of a specific reminiscence approach to promote the well-being of nursing home residents with dementia. Int Psychogeriatr 2004;16:33-49.

153. Haslam C, Haslam SA, Jetten J, et al. The social treatment: the benefits of group interventions in residential care settings. Psychol Aging 2010;25:157-67.

154. Politis AM, Vozzella S, Mayer LS, et al. A randomized, controlled, clinical trial of activity therapy for apathy in patients with dementia residing in long-term care. Int J Geriatr Psychiatry 2004;19:1087-94.

155. Neal M, Barton Wright P. Validation therapy for dementia. Cochrane Database Syst Rev 2003(3):CD001394.

156. Peoples. Validation therapy, versus reality orientation as treatment for disorientated institutionalised elderly [Masters dissertation] Akron: College of Nursing, University of Akron, 1982.

157. Robb SS, Stegman CE, Wolanin MO. No research versus research with compromised results: a study of validation therapy. Nurs Res 1986;35:113-18

158. Toseland RW, Diehl M, Freeman $\mathrm{K}$, et al. The impact of validation group therapy on nursing home residents with dementia. $J$ App Gerontol 1997;16:31-50.

159. Vasse E, Vernooij-Dassen M, Spijker A, et al. A systematic review of communication strategies for people with dementia in residential and nursing homes. Int Psychogeriatr 2010;22:189-200.

160. Cohen-Mansfield J. Agitated behaviors in the elderly. II. Preliminary results in the cognitively deteriorated. J Am Geriatr Soc 1986;34:722-7.

161. Abraha I, Rimland JM, Lozano-Montoya I, et al. simulated presence therapy for dementia: a systematic review protocol. BMJ Open 2016;6:e011007. 
162. Kverno KS, Black BS, Nolan MT. Research on treating neuropsychiatric symptoms of advanced dementia with non-pharmacological strategies, 1998-2008: a systematic literature review. Int Psychogeriatr 2009;21:825-43.

163. Teri L, Logsdon RG, McCurry SM. Nonpharmacologic treatment of behavioral disturbance in dementia. Med Clin North Am 2002;86:641-56. viii.

164. Teri L, Gibbons LE, McCurry SM, et al. Exercise plus behavioral management in patients with Alzheimer disease: a randomized controlled trial. JAMA 2003;290:2015-22.

165. Proctor R, Burns A, Powell HS, et al. Behavioural management in nursing and residential homes: a randomised controlled trial. Lancet 1999;354:26-9.

166. Teri L, Huda P, Gibbons L, et al. STAR: a dementia-specific training program for staff in assisted living residences. Gerontologist 2005;45:686-93.

167. McCurry SM, Gibbons LE, Logsdon RG, et al. Nighttime insomnia treatment and education for Alzheimer's disease: a randomized, controlled trial. J Am Geriatr Soc 2005;53:793-802.

168. Gitlin LN, Winter L, Dennis MP, et al. A biobehavioral home-based intervention and the well-being of patients with dementia and their caregivers: the COPE randomized trial. JAMA 2010;304:983-91.

169. Beck CK, Vogelpohl TS, Rasin JH, et al. Effects of behavioral interventions on disruptive behavior and affect in demented nursing home residents. Nurs Res 2002;51:219-28.

170. Suhr J. Progressive muscle relaxation in the management of behavioural disturbance in Alzheimer's disease. Neuropsychol Rehabil 1999;9:31-44.

171. McCallion P, Toseland RW, Freeman K. An evaluation of a family visit education program. J Am Geriatr Soc 1999;47:203-14.

172. Livingston G, Kelly L, Lewis-Holmes $\mathrm{E}$, et al. A systematic review of the clinical effectiveness and cost-effectiveness of sensory, psychological and behavioural interventions for managing agitation in older adults with dementia. Health Technol Assess 2014;18:1-226. v-vi.

173. Gormley N, Lyons D, Howard R. Behavioural management of aggression in dementia: a randomized controlled trial. Age Ageing 2001;30:141-5.

174. Teri L, Logsdon RG, Peskind E, et al. Treatment of agitation in AD: a randomized, placebo-controlled clinical trial. Neurology 2000;55:1271-8.

175. Bourgeois MS, Burgio LD, Schulz R, et al. Modifying repetitive verbalizations of community-dwelling patients with $A D$. Gerontologist 1997;37:30-9.

176. Moniz Cook ED, Swift K, James I, et al. Functional analysis-based interventions for challenging behaviour in dementia. Cochrane Database Syst Rev 2012;(2):CD006929.

177. Mador JE, Giles L, Whitehead C, et al. A randomized controlled trial of a behavior advisory service for hospitalized older patients with confusion. Int J Geriatr Psychiatry 2004;19:858-63.

178. Burgio L, Stevens A, Guy D, et al. Impact of two psychosocial interventions on white and African American family caregivers of individuals with dementia. Gerontologist 2003;43:568-79.

179. Chenoweth L, King MT, Jeon Y-H, et al. Caring for Aged Dementia Care Resident Study (CADRES) of person-centred care, dementia-care mapping, and usual care in dementia: a cluster-randomised trial. Lancet Neurol 2009;8:317-25.

180. Farran CJ, Gilley DW, McCann JJ, et al. Psychosocial interventions to reduce depressive symptoms of dementia caregivers: a randomized clinical trial comparing two approaches. J Mental Health Aging 2004:10:337-50.

181. Fossey J, Ballard C, Juszczak E, et al. Effect of enhanced psychosocial care on antipsychotic use in nursing home residents with severe dementia: cluster randomised trial. $B M J$ 2006;332:756-61.

182. Gitlin LN, Winter L, Corcoran M, et al. Effects of the home environmental skill-building program on the caregiver-care recipient dyad: 6-month outcomes from the Philadelphia REACH Initiative. Gerontologist 2003:43:532-46.

183. Gonyea JG, O'Connor MK, Boyle PA. Project CARE: a randomized controlled trial of a behavioral intervention group for Alzheimer's disease caregivers. Gerontologist 2006;46:827-32.

184. Huang HL, Shyu Yl, Chen MC, et al. A pilot study on a home-based caregiver training program for improving caregiver self-efficacy and decreasing the behavioral problems of elders with dementia in Taiwan. Int J Geriatr Psychiatry 2003;18:337-45.

185. Losada Baltar A, Izal Fernandez de Troconiz M, Montorio Cerrato I, et al. [Differential efficacy of two psychoeducational interventions for dementia family caregivers]. Rev Neurol 2004;38:701-8.

186. Moniz-Cook E, Elston C, Gardiner E, et al. Can training community mental health nurses to support family carers reduce behavioural problems in dementia? An exploratory pragmatic randomised controlled trial. Int J Geriatr Psychiatry 2008;23:185-91.

187. Zarit SH, Anthony CR, Boutselis M. Interventions with care givers of dementia patients: comparison of two approaches. Psychol Aging 1987;2:225-32.

188. Gitlin LN, Winter L, Dennis MP, et al. Targeting and managing behavioral symptoms in individuals with dementia: a randomized trial of a nonpharmacological intervention. J Am Geriatr Soc 2010;58:1465-74.

189. Finnema E, Dröes RM, Ettema T, et al. The effect of integrated emotion-oriented care versus usual care on elderly persons with dementia in the nursing home and on nursing assistants: a randomized clinical trial. Int J Geriatr Psychiatry 2005;20: 330-43.

190. Schrijnemaekers V, van Rossum E, Candel M, et al. Effects of emotion-oriented care on elderly people with cognitive impairment and behavioral problems. Int J Geriatr Psychiatry 2002;17:926-37.

191. Brodaty H, Arasaratnam C. Meta-analysis of nonpharmacological interventions for neuropsychiatric symptoms of dementia. Am J Psychiatry 2012;169:946-53.

192. Eggenberger E, Heimerl K, Bennett Ml. Communication skills training in dementia care: a systematic review of effectiveness, training content, and didactic methods in different care settings. Int Psychogeriatr 2013;25:345-58.

193. Teri L, McCurry SM, Logsdon R, et al. Training community consultants to help family members improve dementia care: a randomized controlled trial. Gerontologist 2005;45:802-11.

194. Burgio LD, Stevens A, Burgio KL, et al. Teaching and maintaining behavior management skills in the nursing home. Gerontologist 2002;42:487-96.

195. Burgio LD, Allen-Burge R, Roth DL, et al. Come talk with me: improving communication between nursing assistants and nursing home residents during care routines. Gerontologist 2001:41:449-60.

196. Done DJ, Thomas JA. Training in communication skills for informal carers of people suffering from dementia: a cluster randomized clinical trial comparing a therapist led workshop and a booklet. Int J Geriatr Psychiatry 2001;16:816-21.

197. Magai $\mathrm{C}$, Cohen $\mathrm{Cl}$, Gomberg D. Impact of training dementia caregivers in sensitivity to nonverbal emotion signals. Int Psychogeriatr 2002;14:25-38.

198. Staal JA, Sacks A, Matheis R, et al. The effects of Snoezelen (multi-sensory behavior therapy) and psychiatric care on agitation, apathy, and activities of daily living in dementia patients on a short term geriatric psychiatric inpatient unit. Int J Psychiatry Med 2007;37:357-70.

199. Clare L, Linden DE, Woods RT, et al. Goal-oriented cognitive rehabilitation for people with early-stage Alzheimer disease: a single-blind randomized controlled trial of clinical efficacy. Am J Geriatr Psychiatry 2010;18:928-39.

200. Gitlin LN, Winter L, Burke J, et al. Tailored activities to manage neuropsychiatric behaviors in persons with dementia and reduce caregiver burden: a randomized pilot study. Am J Geriatr Psychiatry 2008;16:229-39.

201. Gitlin LN, Corcoran M, Winter L, et al. A randomized, controlled tria of a home environmental intervention: effect on efficacy and upset in caregivers and on daily function of persons with dementia. Gerontologist 2001;41:4-14.

202. Gaugler JE, Kane RL. Families and assisted living. Gerontologist 2007;47(suppl 1):83-99.

203. Collet J, de Vugt ME, Verhey FR, et al. Efficacy of integrated interventions combining psychiatric care and nursing home care for nursing home residents: a review of the literature. Int $J$ Geriatr Psychiatry 2010;25:3-13.

204. Zimmerman S, Anderson WL, Brode S, et al. Systematic review: effective characteristics of nursing homes and other residential long-term care settings for people with dementia. J Am Geriatr Soc 2013;61:1399-409.

205. Whall AL, Black ME, Groh CJ, et al. The effect of natural environments upon agitation and aggression in late stage dementia patients. Am J Alzheimers Dis Other Demen 1997;12:216-20.

206. Hicks-Moore SL, Robinson BA. Favorite music and hand massage: two interventions to decrease agitation in residents with dementia. Dementia 2008;7:95-108.

207. Potter R, Ellard D, Rees K, et al. A systematic review of the effects of physical activity on physical functioning, quality of life and depression in older people with dementia. Int J Geriatr Psychiatry 2011;26:1000-11.

208. Thuné-Boyle IC, lliffe $S$, et al. The effect of exercise on behavioral and psychological symptoms of dementia: towards a research agenda. Int Psychogeriatr 2012;24:1046-57. 
209. Burgener SC, Yang Y, Gilbert R, et al. The effects of a multimodal intervention on outcomes of persons with early-stage dementia. Am J Alzheimers Dis Other Demen 2008;23:382-94.

210. Rolland Y, Pillard F, Klapouszczak A, et al. Exercise program for nursing home residents with Alzheimer's disease: a 1-year randomized, controlled trial. J Am Geriatr Soc 2007;55:158-65.

211. Steinberg M, Leoutsakos JM, Podewils LJ, et al. Evaluation of a home-based exercise program in the treatment of Alzheimer's disease: the Maximizing Independence in Dementia (MIND) study. Int J Geriatr Psychiatry 2009;24:680-5.

212. Bernabei V, De Ronchi D, La Ferla T, et al. Animal-assisted interventions for elderly patients affected by dementia or psychiatric disorders: a review. J Psychiatr Res 2013;47:762-73.

213. Churchill M, Safaoui J, McCabe BW, et al. Using a therapy dog to alleviate the agitation and desocialization of people with Alzheimer's disease. J Psychosoc Nurs Ment Health Serv 1999;37:16-22.

214. McCabe BW, Baun MM, Speich D, et al. Resident dog in the Alzheimer's special care unit. West J Nurs Res 2002;24:684-96.

215. Richeson NE. Effects of animal-assisted therapy on agitated behaviors and social interactions of older adults with dementia. Am J Alzheimers Dis Other Demen 2003;18:353-8.
216. Libin A, Cohen-Mansfield J. Therapeutic robocat for nursing home residents with dementia: preliminary inquiry. Am J Alzheimers Dis Other Demen 2004;19:111-16.

217. Motomura N, Yagi T, Ohyama H. Animal assisted therapy for people with dementia. Psychogeriatrics 2004;4:40-2.

218. Sellers DM. The evaluation of an animal assisted therapy intervention for elders with dementia in long-term care. Act Adapt Aging 2006;30:61-77.

219. Brush JA, Meehan RA, Calkins MP. Using the environment to improve intake for people with dementia. Alzheimer's Care Today 2002;3:330-8.

220. Koss E, Gilmore G. Environmental interventions and functional ability of AD patients. In: Vellas, B., Fitten, J. and Frisoni, G. eds. Research and practice in Alzheimer's disease. Paris: Springer, 1998:185-191.

221. Frisoni GB, Gozzetti A, Bignamini V, et al. Special care units for dementia in nursing homes: a controlled study of effectiveness. Arch Gerontol Geriatr 1998;26:215-24.

222. Fontana Gasio P, Kräuchi K, Cajochen C, et al. Dawn-dusk simulation light therapy of disturbed circadian rest-activity cycles in demented elderly. Exp Gerontol 2003;38:207-16. 
Corrections: Systematic review of systematic reviews of non-pharmacological interventions to treat behavioural disturbances in older patients with dementia. The SENATOROnTop series

Abraha I, Rimland JM, Trotta FM, et al. Systematic review of systematic reviews of nonpharmacological interventions to treat behavioural disturbances in older patients with dementia. The SENATOR-OnTop series. BMJ Open 2017;7:e12759. doi: 10.1136/ bmjopen-2016-012759

The authors would like to thank dr. Reisberg and colleagues for their appreciation and for their valuable comments our manuscript. Reisberg and colleagues correctly noticed the discrepancy in presentation of the categorization of the non-pharmacological intervention between the main text and the abstract. The authors would like to underline that the categorization of the interventions in the main text is the correct one and therefore the results in the abstract should be modified as follows:

38 SRs and 129 primary studies were identified, comprising the following categories of non-pharmacological interventions: (1) sensory stimulation interventions (25 SRs, 66 primary studies) that encompassed: shiatsu and acupressure, aromatherapy, massage/ touch therapy, light therapy, sensory garden and horticultural activities, music/dance therapy, dance therapy, snoezelen multisensory stimulation therapy, transcutaneous electrical nerve stimulation; (2) cognitive/emotion-oriented interventions (13 SRs; 26 primary studies) that included cognitive stimulation, reminiscence therapy, validation therapy, simulated presence therapy; (3) behaviour management techniques (6 SRs; 22 primary studies); (4) Multicomponent interventions (3SR; four primary studies); (5) other therapies (5 SRs, 15 primary studies) comprising exercise therapy, animal-assisted therapy, special care unit and dining room environment-based interventions.

Please note that the numbers provided are absolute numbers and the following reviews can fall in different categories as they considered different types of non-pharmacological interventions and thus explain any discrepancy in numbers: Seitz $2012^{1}$ that considered aromatherapy, light therapy, music/dance therapy, snoelzen therapy, and reminiscence therapy; O'Neil $2011^{2}$ that considered snoelzen, behavioural management techniques; Chaudhury $2013^{3}$ that considered light therapy and the role of physical environment in supporting person-centred dining in LTC; and Whear $2014^{4}$ that examined the effect of improved lighting and table-setting contrast in a dining room environment. In addition, two primary studies fell in two different categories: Proctor $1999^{5}$ was in reviews that dealt with behavioural management techniques (BMT) and one review that, within the multicomponent interventions, examined the combined effect of BMT with educational intervention; and Teri $2003^{6}$ was considered in the BMT reviews and the exercise-based reviews.

In addition, the authors want to point out the following minor corrections in the main text: page 17 under the paragraph on Behavioural management techniques it should read 'One review of reviews and five SRs' instead of 'One overview of reviews and four SRs'.

page 21, the authors missed describing the seventh study with repeated measures design: "In the a small repeated measures study Mossello et al, evaluated the effect of animal assisted therapy in ten patients attending an Alzheimer Day Care Centre. The design consisted in 2 weeks' pre-intervention, 3 weeks' control activity with plush dogs, and 3 weeks' animal assisted therapy. NPI was used to assess BPSD and CMAI to assess mood; both outcomes remained unchanged across the study. Anxiety measured with NPI decreased during animal assisted therapy $(\mathrm{p}=0.04)^{7}$.

Open Access This is an Open Access article distributed in accordance with the Creative Commons Attribution Non Commercial (CC BY-NC 4.0) license, which permits others to distribute, remix, adapt, build upon this work non-commercially, and license their derivative works on different terms, provided the original work is properly cited and the use is non-commercial. See: http://creativecommons.org/licenses/by-nc/4.0/ 
(c) Article author(s) (or their employer(s) unless otherwise stated in the text of the article) 2017. All rights reserved. No commercial use is permitted unless otherwise expressly granted.

BMJ Open 2017;7. doi:10.1136/bmjopen-2016-012759corr1

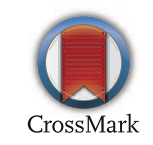

